\title{
Improved Constraints on Models of Glacial Isostatic Adjustment: A Review of the Contribution of Ground-Based Geodetic Observations
}

\author{
Matt A. King • Zuheir Altamimi • Johannes Boehm • Machiel Bos • \\ Rolf Dach • Pedro Elosegui • François Fund • Manuel Hernández-Pajares • \\ David Lavallee • Paulo Jorge Mendes Cerveira • Nigel Penna • \\ Riccardo E. M. Riva • Peter Steigenberger • Tonie van Dam • \\ Luca Vittuari $\cdot$ Simon Williams $\cdot$ Pascal Willis
}

Received: 19 October 2009/Accepted: 27 May 2010/Published online: 16 June 2010

(C) The Author(s) 2010. This article is published with open access at Springerlink.com

\begin{abstract}
The provision of accurate models of Glacial Isostatic Adjustment (GIA) is presently a priority need in climate studies, largely due to the potential of the Gravity Recovery and Climate Experiment (GRACE) data to be used to determine accurate and continent-wide assessments of ice mass change and hydrology. However, modelled GIA is
\end{abstract}

M. A. King $(\bowtie) \cdot$ N. Penna

School of Civil Engineering and Geosciences, Newcastle University, Cassie Building,

Newcastle upon Tyne NE1 7RU, UK

e-mail: m.a.king@ncl.ac.uk

Z. Altamimi

Institut Géographique National, ENSG/LAREG, 6 \& 8 Avenue Blaise Pascal,

77455 Champs-sur-Marne, France

J. Boehm

Institute of Geodesy and Geophysics E1281, Vienna University of Technology,

Gusshausstrasse 27-29, 1040 Vienna, Austria

M. Bos

CIMAR/CIIMAR, Centro Interdisciplinar de Investigação Marinha e Ambiental Universidade do Porto, Rua dos Bragas 289, 4050-123 Porto, Portugal

R. Dach

Astronomical Institute, University of Bern, Sidlerstrasse 5, 3012 Bern, Switzerland

P. Elosegui

Institute for Space Sciences, CSIC-IEEC, Nexus 201, Gran Capita 2, 08034 Barcelona, Spain

F. Fund

Laboratoire de Géomatique et de Géodésie (L2G), ESGT/CNAM, 1 Boulevard Pythagore, 72000 Le Mans, France

F. Fund

CNRS, Laboratoire de Planétologie et Géodynamique, UMR 6112, UFR des Sciences et des Techniques, Université de Nantes, Nantes Atlantique Université, 2 rue de la Houssinière, BP 92208, Nantes Cedex 3 44322, France 
uncertain due to insufficient constraints on our knowledge of past glacial changes and to large simplifications in the underlying Earth models. Consequently, we show differences between models that exceed several $\mathrm{mm} /$ year in terms of surface displacement for the two major ice sheets: Greenland and Antarctica. Geodetic measurements of surface displacement offer the potential for new constraints to be made on GIA models, especially when they are used to improve structural features of the Earth's interior as to allow for a more realistic reconstruction of the glaciation history. We present the distribution of presently available campaign and continuous geodetic measurements in Greenland and Antarctica and summarise surface velocities published to date, showing substantial disagreement between techniques and GIA models alike. We review the current state-of-the-art in ground-based geodesy (GPS, VLBI, DORIS, SLR) in determining accurate and precise surface velocities. In particular, we focus on known areas of need in GPS observation level models and the terrestrial reference frame in order to advance geodetic observation precision/accuracy toward $0.1 \mathrm{~mm} /$ year and therefore further constrain models of GIA and subsequent present-day ice mass change estimates.

Keywords Glacial isostatic adjustment (GIA) - Ice sheet mass balance · Geodesy · Antarctica · Greenland · GPS · VLBI · DORIS · SLR

M. Hernández-Pajares

Applied Mathematics IV, Universitat Politècnica de Catalunya, Jordi Girona, 1-3,

Campus Nord Mod C3 UPC, ES 08034 Barcelona, Spain

D. Lavallee

Delft Institute of Earth Observation and Space Systems, Delft University of Technology,

2600 GB Delft, The Netherlands

P. J. Mendes Cerveira

BEWAG Geoservice GmbH, Eisenstadt, Austria

R. E. M. Riva

Delft Institute of Earth Observation and Space Systems, Delft University of Technology, Kluyverweg 1, 2629 HS Delft, The Netherlands

\section{P. Steigenberger}

Institut für Astronomische und Physikalische Geodäsie, Technische Universität München, Arcisstraße 21, 80333 München, Germany

T. van Dam

Faculté des Sciences, de la Technologie et de la Communication, University of Luxembourg,

6, rue Richard, Coudenhove-Kalergi 1359, Luxembourg

L. Vittuari

Dipartimento di Ingegneria delle Strutture, dei trasporti, delle acque, del rilevamento, del territorio, Viale Risorgimento, 2 Bologna, Italy

S. Williams

National Oceanography Centre, Joseph Proudman Building, 6 Brownlow Street,

L3 5DA Liverpool, UK 


\section{Introduction}

Glacial Isostatic Adjustment (GIA) is the global response of the solid Earth to changes in ice load following the Last Glacial Maximum. It is the result of the modification of the Earth's gravitational field as a consequence of surface mass redistribution and of the ability of the Earth to deform. The speed of the response is largely governed by the viscosity of the mantle, and full isostatic adjustment requires thousands of years. The consequence is that GIA is ongoing and may be observed by modern-day geodetic techniques, with geodetic signatures seen in the Earth's rotation rate, gravity field, geocentre and shape (Chao et al. 2000). For example, the deformation of the solid Earth still may exceed $0.01 \mathrm{~m} /$ year in locations of former or reduced ice sheets (e.g., North America, Scandinavia, Greenland or Antarctica). Geodetic measurements, therefore, must consider GIA as either a source of noise (requiring accurate GIA models to remove it) or signal (with opportunity to understand GIA processes such as Earth rheology and ice sheet history).

Recently, there has been renewed interest in GIA due mainly to the Gravity Recovery and Climate Experiment (GRACE) satellite mission (Tapley et al. 2004) which requires, when attempting to recover polar ice mass change, the removal of all other signals of horizontal mass redistribution. GIA is particularly problematic in Antarctica, and to a lesser but still important extent Greenland, due to uncertainties in modelling it. As a result, GRACE-derived estimates of ice mass change for Antarctica are presently overwhelmed by GIA model uncertainty (Chen et al. 2006a; Ramillien et al. 2006; Velicogna and Wahr 2006; Sasgen et al. 2007). This uncertainty is not well known due to a lack of independent data sets, but has been generally characterised by either differencing two models (e.g., Velicogna and Wahr 2006), taking the uncertainty to be $100 \%$ of the signal (Chen et al. 2006b), or by exploring GIA model parameter space in the form of variations to Earth rheological parameters (lithospheric thickness, upper and lower mantle viscosity) and ice sheet history (e.g., Ramillien et al. 2006; Barletta et al. 2008). Indeed, the lack of robust information on model uncertainty has led some to leave the uncertainty unquantified (Chen et al. 2006a; Luthcke et al. 2006).

GIA models are generally data poor in polar regions and new constraints from precise and geographically widespread 3-d surface velocity measurements represent one of the best ways to constrain them (Milne et al. 2001). In this paper, we briefly review the current level of uncertainty in GIA modelling and then review in detail the state-of-the-art in terms of geodetic observation of GIA, limiting ourselves to ground-based (geometric) geodetic observations. We pay particular attention to our present-day ability to exploit ground-based geodetic techniques to provide accurate and precise 3-d surface velocities in key regions of ongoing GIA. Geographically, we focus on the two major, present-day ice sheets: Greenland and Antarctica. Within the scope of the International Polar Year (2007-2009) programme POLENET (www.polenet.org), dozens of new permanent Global Positioning System (GPS) receivers are being deployed in Antarctica and Greenland, and further networks are planned in the coming years. As we shall show, further model advances and

P. Willis

Institut Géographique National, Direction Technique, 2, avenue Pasteur, 94165 Saint-Mandé, France

P. Willis

Institut de Physique du Globe de Paris (IPGP, Paris 7, CNRS), 5 rue Thomas Mann, UFR STEP, Bat Lamarck, Case 7011, 75205 Paris, France 
equipment deployments are required before these new data may be totally exhausted in the pursuit of new constraints on GIA models.

With this aim in mind the "European Cooperation in the field of Scientific and Technical Research (COST)" programme has funded Action ES0701 during 2008-2012. The main objective of the Action is to place improved constraints on models of GIA through the development of state-of-the-art surface velocity measurements with the consequent production of new ice mass change estimates for the major ice sheets. One particular focus is on the contribution of geodetic measurements of Earth surface displacement using GPS, Doppler Orbitography and Radiopositioning Integrated by Satellite (DORIS), Very Long Baseline Interferometry (VLBI) and Satellite Laser Ranging (SLR). At the commencement of the Action, this review paper provides a summary of the state-of-the-art of the contribution of geometric geodesy to applying new constraints on models of GIA and lists the major obstacles in terms of observation and data analysis that must be overcome in order to provide optimal new constraints on GIA models. We commence in the next section with a summary of the present day knowledge of GIA through models and previously published GPS measurements of it.

\section{Background}

\subsection{Modelling GIA and Present-Day Model Uncertainty}

Isostatic adjustment takes place because a change in surface load induces a stress gradient within the Earth, which forces mantle material to flow towards an isostatic configuration, where gravitational energy is at its minimum. This process is known as viscoelastic relaxation and occurs on timescales varying from decades to millions of years, depending on mantle viscosity. Since the solid Earth response is delayed with respect to changes in the surface forcing, GIA is not synchronous with the Earth's glacial history: for this reason we are still observing the effect of the last deglaciation, even if most of the ice has already disappeared a few thousand years ago. In addition to the direct interaction between the ice load and the solid Earth, the induced gravity changes cause a redistribution of ocean water, which in turn represents an additional surface load. Modelling GIA, therefore, requires to take into account in a gravitationally self-consistent way the deformation of the solid Earth, the change in ice load and the redistribution of ocean water. This is considered by solving the sea-level equation (Farrell and Clark 1976), which in its recent realizations includes shoreline migration and tidal forcing due to perturbations of the Earth rotation (Mitrovica and Milne 2003).

As a result of the ice-earth-ocean interaction, modelling GIA requires an accurate knowledge of the past glacial history and of the Earth's structure. By glacial history we mean the evolution of the ice sheets during the whole glacial cycle, where both spatial distribution and timing of melt are equally important. Migration of the edges of the past ice sheets is mainly constrained by geological records, while ice thickness is mainly constrained by relative sea level records, where near-field records are more sensitive to the local ice distribution and far-field records are more sensitive to the total amount of ice melt. As far as the Earth's parameterization is concerned, this requires the consideration of the 3-d structure as well as of its rheology (i.e., the relation between stress and strains). Lateral heterogeneities in structure originate from plate tectonics, the vertical temperature gradient through the lithosphere, and compositional phase changes throughout the mantle. A rheological model is necessary because it determines how rocks respond to stress changes, also within a single compositional layer (Ranalli 1995). 
Due to the complexity of the GIA process, and the relatively poor field evidence, global GIA studies usually constrain the glacial history in combination with a one-dimensional (vertically stratified, laterally homogeneous) Earth model, assuming a linear (Maxwelltype) rheology. In this way, since elastic properties are independently obtained from seismologic studies (e.g., Dziewonski and Anderson 1981), the inversion process can be optimized to constrain the ice history and the vertical viscosity structure of the Earth (e.g., Peltier 1976; Nakada and Lambeck 1989; Tushingham and Peltier 1991). The resulting ice history and viscosity structure are coupled, meaning that unrealistic GIA predictions might result from using those deglaciation models in combination with arbitrary viscosity profiles. However, large errors and trade-offs in the sea level records, unevenly distributed and difficult to date, cause large uncertainties in the resulting models and leave abundant room for independent improvements in both the ice history and the viscosity structure (e.g., Mitrovica and Forte 2004).

Geodetic measurements may improve constraints to GIA models both globally and locally. The global GIA signal, i.e. its large scale features, mainly depends on the total amount of ice, the location of the main ice domes, and the viscosity of the deep mantle. Measurements of changes in the Earth's rotation can help with constraining these parameters. Local GIA, on the contrary, is mainly controlled by the specific ice distribution, by upper mantle viscosity and by the thickness of the lithosphere: here, accurate GPS measurements can potentially improve existing models. Since glacial histories are mainly constrained by means of relative sea level records, they often lack the spatial resolution necessary to accurately constrain the complex evolution of the ice sheets. The fact that the inversion is usually performed on the basis of a one-dimensional Earth with linear rheology is likely biasing the final solution, in a way that is very difficult to estimate. Though the geodetic information is practically limited to the present-day snapshot, the dense spatial distribution and the high accuracy of modern space geodesy measurements can substantially reduce the range of acceptable solutions (e.g., Argus and Peltier 2010). In other words, it is reasonable to expect that new constraints on 3-d surface velocities will improve both the local Earth parameterization and the glacial history, while preserving the fit to the available relative sea level records.

To demonstrate some differences between GIA models, in Figs. 1 and 2 we show plots of horizontal and vertical deformation for a suite of models. Figure 1 includes also Canada and Fennoscandia, because these areas are necessary to understand the behaviour of the various models over Greenland.

In the top line of Fig. 1, we show results obtained using ice history ICE-5G (Peltier 2004) for Greenland and surrounds. Panels a and b show results by Wang et al. (2008): panel (a) shows results for a laterally homogeneous Earth, while panel (b) shows results for the laterally heterogeneous structure which provides the best fit to the global Relative Sea Level (RSL) record, the uplift rates in Laurentide and Fennoscandia and the BIFROST horizontal velocity data (Scherneck et al. 2001). In their approach, Wang et al. (2008) employ a Coupled Laplace Finite Element method to predict the GIA response on a spherical, self-gravitating, compressible, viscoelastic Earth with self-gravitating oceans. Lateral heterogeneities in mantle viscosity are introduced on the basis of the lateral SHwave (horizontal shear wave) velocity anomalies given in the seismic tomographic model S20A of Ekstrom and Dziewonski (1998). The degree 1 component of the load is removed in advance from the computations, which approximately fixes the reference frame to the centre of mass of the solid Earth (CE, see Blewitt 2003). In the bottom line of Fig. 1, we show results according to Klemann et al. (2008), where panel (c) shows results for a laterally homogeneous Earth model, while panel (d) shows the effect of including a 

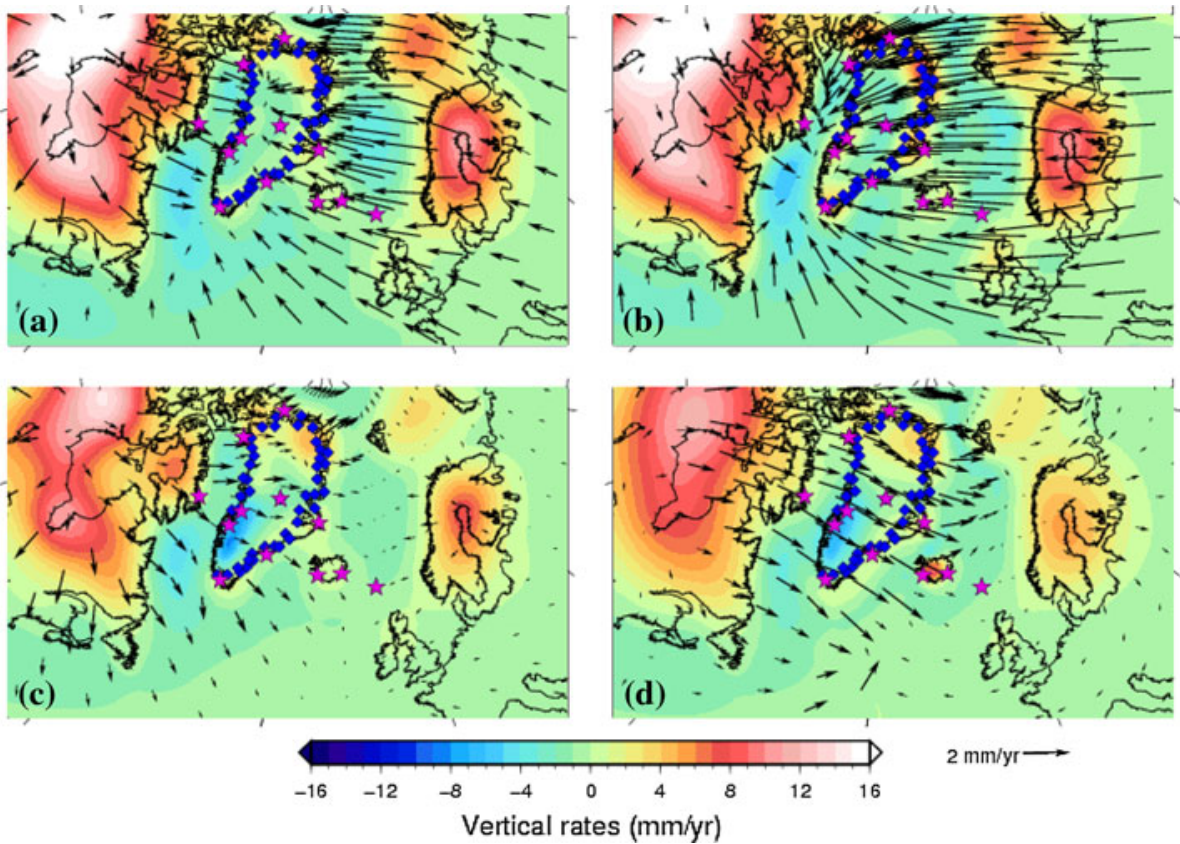

Fig. 1 Surface displacement rates due to GIA in the Northern Hemisphere, for ice history ICE-5G (Peltier 2004). a-b are obtained from model results according to Wang et al. (2008), for Earth model RF3S20, with scaling factor $\mathbf{a} \beta=0$ and $\mathbf{b} \beta=0.2$. c-d are obtained from model results by Klemann et al. (2008), with a simplification of Earth model VM2, for $\mathbf{c}$ a laterally homogeneous Earth and $\mathbf{d}$ a model with a laterally heterogeneous lithosphere. Purple stars indicate GPS sites with continuous long-term ( $>1,000$ days) observations; blue diamonds GPS sites with short-term continuous/campaign observations at the time of writing

laterally heterogeneous lithospheric structure, with plates loosely connected by low-viscosity zones but an otherwise homogeneous mantle structure. Also this model is spherical, self-gravitating and linear viscoelastic, but in this case incompressible. The reference frame is represented by the centre of mass of the whole system (CM: solid Earth plus surface load).

In all panels, uplift is concentrated where the largest ice domes were located (in Laurentide and Fennoscandia). Differences in vertical rates are several $\mathrm{mm} / \mathrm{year}$, with the largest differences over the regions of greatest uplift. However, differences in Greenland are evident, especially in the northeast and southwest. Large differences also appear when we compare predictions of horizontal motions. Results by Wang et al. (2008) over the Eurasian plate are dominated by a westward motion, which is largely amplified by the introduction of lateral heterogeneities. Since horizontal motions are rather small between North America and Greenland, the result is a longitudinal compression of Greenland. Results by Klemann et al. (2008), on the contrary, show a much smaller background motion over Eurasia. The addition of plate boundaries has the main effect of amplifying the motions over the North American plate, with a small impact on the internal deformation of Greenland.

Those examples highlight a number of differences between GIA model results:

- the difference between panels (a) and (c), both laterally homogeneous models, is mainly due to a different choice in the mantle viscosity profile; in particular, the 


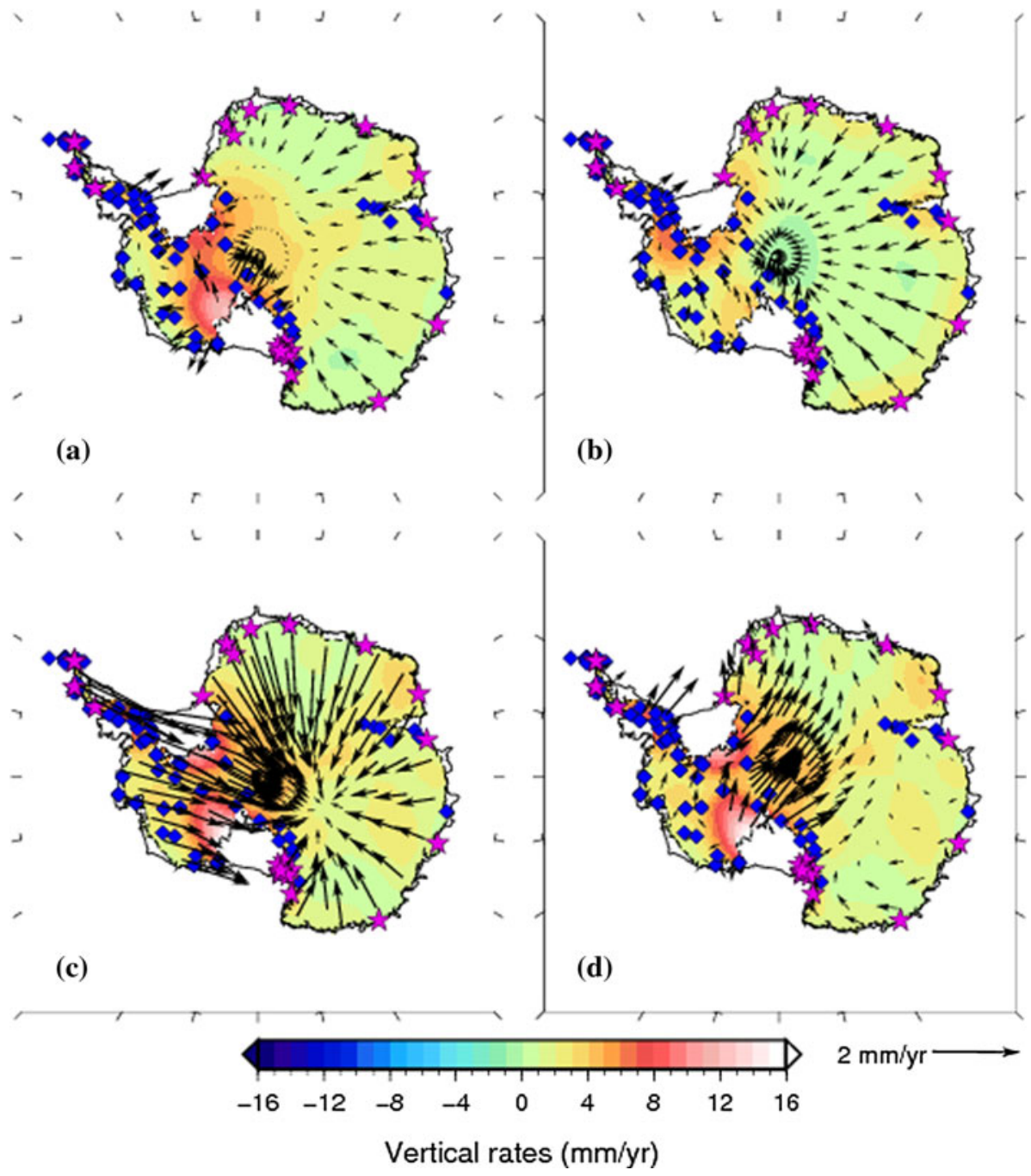

Fig. 2 Surface displacement rates due to GIA over Antarctica. a-b are for a laterally homogeneous model, with Earth model VM2 and a ice history ICE-5G (Peltier 2004), and b ice history IJ05 (Ivins and James 2005). c-d are for two laterally heterogeneous Earth models: $\mathbf{c}$ as in Fig. 1b and d as in Fig. 1d. Stars and diamonds as in Fig. 1

dominant motion over Eurasia is due to the fact that most of the lower mantle in Wang et al. (2008) has a viscosity that is three times as large as in Klemann et al. (2008). Further differences would be evident if different ice models were considered (see below);

- the introduction of lateral heterogeneities in mantle viscosity (panels a vs. b) extends the area of influence of the relaxation signal coming from Fennoscandia;

- the introduction of lateral heterogeneities in lithospheric thickness, including plate boundaries (panels c vs. d), extends the area of influence of the relaxation signal from North America; 
- internal deformation over Greenland (mainly due to the deglaciation history over Greenland itself) is largely overprinted by the influence of the relaxation signal coming from Fennoscandia (panel b) and from North America (panel d): for this reason, accurate referencing of geodetic measurement will be necessary to validate GIA model results;

- the reference frame of GIA models is not always the same (Argus 1996).

Figure 1 also includes the regions where, to date, the value of ground-based geodetic studies has been demonstrated most clearly: in Laurentide (e.g., Sella et al. 2007), and especially Fennoscandia (e.g., Milne et al. 2001; Johansson et al. 2002; Milne et al. 2004). In these cases, the geodetic data has been used to show agreement with the models in the broadest sense, but also highlight important differences and hence enable new constraints to be made on GIA modelling (Milne et al. 2001; Whitehouse et al. 2006).

In the case of Antarctica, large differences are also present between various model results, as we show in Fig. 2. In panel (a), we show results for a laterally homogeneous model, with incompressible linear rheology, for ice history ICE-5G (Peltier 2004) and a simplification of viscosity structure VM2, represented in the CM reference frame. Most of the vertical deformation is concentrated over West Antarctica, in particular in two areas: along Siple Coast (lower dome) and next to the Ronne and Filchner ice shelves (upper dome). Horizontal motions are directed away from the uplifting domes in West Antarctica and away from the coast (inland) over East Antarctica. In panel (b), we show results for ice history IJ05 (Ivins and James 2005), and the same Earth model. Due to large differences in the spatial distribution of the ice load and melt histories, the resulting pattern is completely different with respect to the previous case. In particular, in West Antarctica the largest vertical signal is now concentrated at the base of the Peninsula, while the signal over Siple Coast is reduced by a factor of three. Over East Antarctica, vertical GIA is concentrated along the coast, resulting in increased horizontal motions towards the interior. Note that the same contribution from the Northern Hemisphere has been added to both results, meaning that the differences between panels (a) and (b) are entirely due to Antarctic GIA. Results from the two bottom panels are for laterally heterogeneous models, where panel (c) is taken from Wang et al. (2008) (i.e., same dataset as Fig. 1b) and panel (d) from Klemann et al. (2008) (i.e., same dataset as Fig. 1d). Again, the introduction of lateral heterogeneities has a large effect on GIA model results. This is mainly due to the fact that most of the changes in ice load are localized over West Antarctica, which is characterized by a much thinner lithosphere and a warmer thermal regime than the cratonic East Antarctica (that has an old, and therefore thick and cold, lithosphere). In particular, horizontal motions are largely affected by the heterogeneous Earth structure, both in magnitude and direction.

As far as the possibility of validating model results by means of ground-based measurements is concerned (as discussed below, this is predominantly GPS), the regions of largest uplift are increasingly well observed. Larger differences between the various models are expected from horizontal motions: however, considering that relative motions are at the $\mathrm{mm} /$ year level and occur over a spatial scale of a few thousand kilometres, a crucial role will be played by the choice of an appropriate (stable and accurate) reference frame.

Besides GIA, a large signal is due to the elastic response to current melt: in Fig. 3 we have computed the response of a self-gravitating compressible Earth to changes in surface load. Since the debate about the actual amount of melt is still open, we have chosen two of the most recent publications as reference for the surface mass loss, without implying that 


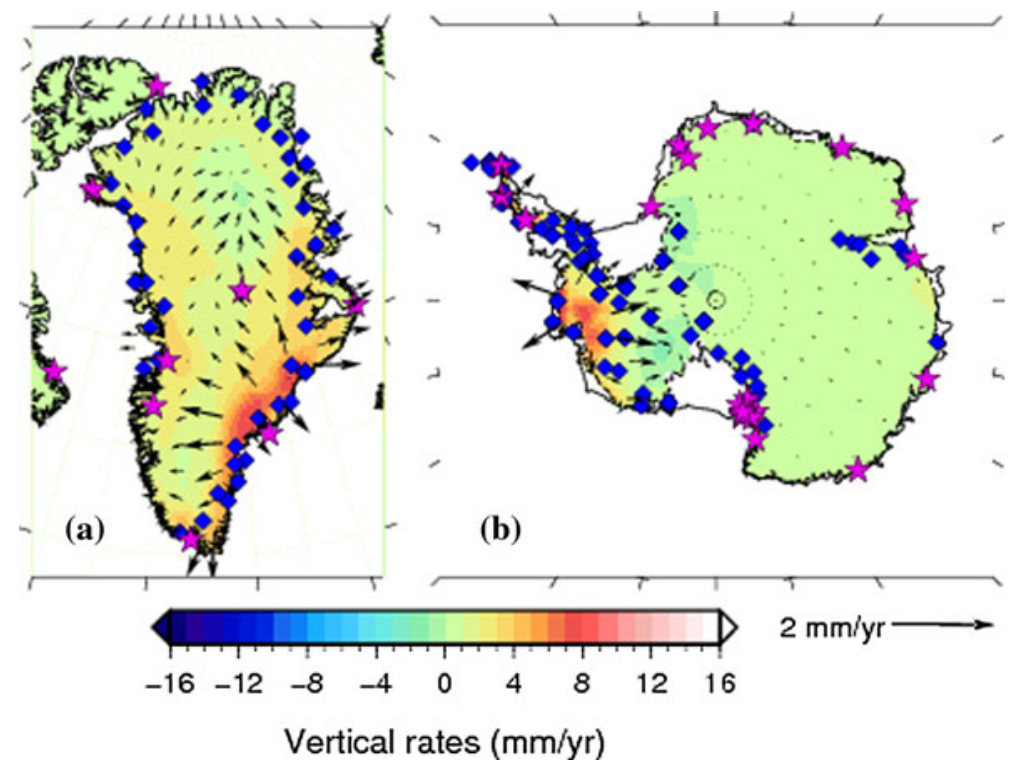

Fig. 3 Surface displacement rates due to present-day melt over a Greenland [ice mass change estimates from Wouters et al. (2008)] and b Antarctica [ice mass change estimates from Rignot et al. (2008)]. Stars and diamonds as in Fig. 1

those results are more accurate than others available in the literature. For Greenland (panel a) we have used the results of an inversion of GRACE gravity measurements (Wouters et al. 2008). For Antarctica we have used results based on the mass budget approach (Rignot et al. 2008) and distributed the mass change per basin over the fast-flowing ice streams. Both horizontal and vertical motions are concentrated over the regions where most of the mass loss takes place, i.e. the south-east coast of Greenland and along the Amundsen Sea Embayment in Antarctica. The magnitude of the elastic rebound is comparable to that of GIA, but it is localized in different areas, offering the possibility of discriminating it from the GIA signal using geodetic techniques. This is especially true for Greenland, because of the more uniform station coverage around the southern coast, and for the Antarctic Peninsula, which is expected to be losing a considerable amount of mass over a relatively small area.

In summary, what will be the added value of new, more accurate, GPS measurements with respect to our understanding of GIA and present-day ice mass balance? The task of improving GIA modelling is extremely challenging, because of the almost instantaneous time-span covered by GPS measurements. However, the differences between various GIA models are large enough to make GPS a powerful validation tool. This is especially true if accurate (sub-millimetre) and widespread (global) measurements of both vertical and horizontal displacement become available. More accurate and realistic GIA results will in turn improve the determination of present-day surface mass balance, especially in relation to GRACE measurements. In this respect, if the spatial coverage of GPS data becomes dense enough, displacement measurements might even locally replace GIA model results. However, such a dense network is far from being realised, if logistic and technical issues will ever allow it. Therefore we discuss results from such geodetic networks next. 


\subsection{Ground-Based Geodetic Arrays and Present-Day Observations of GIA}

As shown in Figs. 1 and 2, GIA is a process that results in a 3-d deformation of the solid Earth. Whilst vertical displacements are often the largest, this is not always the case as is evident at the fore bulge. Indeed, the horizontal components of GPS are often substantially more precise than the vertical component and may therefore yield information of use to testing GIA models with shorter time series (after the removal of tectonic motion signals). In this section we consequently consider observation models which affect the accuracy and precision of 3-d site velocities.

Due to its portability, price and weight, GPS has become the most common geodetic technique deployed to study GIA processes. Until very recently, geodetic GPS observations in Greenland and Antarctica were sparse in time and space. For many years, it was seen as almost impossible to continuously power a GPS receiver through the polar winter, where solar power was insufficient for up to 6 months and wind generators proved to be consistently unreliable. As a result, it was common for sites to run only in the summer months even if they were permanently installed. Many of these technological limitations have now been overcome (Willis 2008), partially assisted by low-power GPS receivers equipped with large memory cards, and GPS receivers have now operated without failure through the entire winter. Taking advantage of these advances, efforts are now being undertaken to dramatically increase the spatial coverage of GPS observations.

Whilst velocities are available using data from other ground-based geodetic techniques in Antarctica and Greenland, including VLBI (two in Antarctica) and DORIS (one in Greenland and four in Antarctica), the overwhelming direct contribution to GIA measurement is from GPS and this technique will therefore be discussed in most detail here (see Sect. 3). However, all techniques (VLBI, SLR, DORIS and GPS) are used to realise the International Terrestrial Reference System (ITRS). Its realization, the ITRF, provides a reference frame for working with geodetic observations and its origin, orientation and scale definitions have a fundamental impact on the use and interpretation of station displacements. The ITRS provides the physical and conventional underpinnings of the ITRF and is crucial for correct application of observation models and scientific interpretation. The accuracy of the other techniques, as impacts on the accuracy of the ITRF, is discussed in Sect. 4.

\subsubsection{Greenland}

Continuous GPS measurements in Greenland started in the mid-1990 s with the contemporaneous installation, on bedrock, of the permanent stations at Thule Air Base and Kellyville, off the western edge of the Greenland ice sheet (Fig. 1), and at Kulusuk, off its eastern margin, by the Danish National Survey and Cadastre (KMS) and the University of Colorado. Except for a few new stations such as Scoresbysund and Qaqortoq that were added over subsequent years, the GPS network remained essentially the same for the next decade or more. The mapping of the 3-d velocity field associated with GIA requires a continuously operating GPS network that is spatially dense and ideally homogeneous (e.g., Johansson et al. 2002). This is particularly important in the case of Greenland where the viscoelastic GIA signal and the elastic response due to present-day ice mass changes (e.g., Khan et al. 2007) occur concurrently, and their separation is not possible without independent constraints (e.g., Wahr et al. 1995). Fortunately, such a GPS network has come to exist most recently. Indeed, the installation of $\sim 40$ continuous GPS stations along most of the perimeter of Greenland's ice sheet (Fig. 1) since 2007-2008 by the international Polar 
Earth Observing Network (POLENET) should represent a significant improvement towards precise determination of ice mass variability in Greenland.

Such improvement is sorely needed since our current understanding of GIA in Greenland is still rather limited. Using some of the early GPS measurements from stations Kellyville and Kulusuk, Wahr et al. (2001) first reported vertical velocity estimates at those locations, and concluded that they were associated with the ongoing viscoelastic response of the Earth to changes in Greenland's ice mass since the last glacial maximum. Interestingly, at Kellyville they found an anomalous subsidence of $5.8 \pm 1.0 \mathrm{~mm} / \mathrm{year}$, which was interpreted as the result of the $\sim 50 \mathrm{~km}$ re-advance of the western margin of the ice sheet in this region during the past 4000 years that ensued the major ice retreat phase since the early Holocene. Using GPS measurements spanning seven years from occupations at 10 sites in the southwest flank of the ice sheet, Dietrich et al. (2005) mapped the pattern of subsidence in this region, which is characterized by an overall eastwest gradient of $\sim 4 \mathrm{~mm} /$ year, with subsidence largest at the present location of the ice sheet margin and decreasing westward towards the Greenland coast. Together, these two studies demonstrate the potential of GPS to constrain the spatio-temporal pattern on models of deglaciation.

It is also interesting to note that though both studies report subsidence for the only GPS station in common, Kellyville, their estimates of vertical velocity differ by $2.7 \mathrm{~mm} / \mathrm{year}$, or approximately twice their combined estimated error. Moreover, the latest estimate of Kellyville subsidence, $1.2 \pm 1.1 \mathrm{~mm} /$ year, by Khan et al. (2008) using a dataset that expands that of Wahr et al. (2001) by including seven more years of data at Kellyville and Kulusuk and adding the three continuous GPS sites at Thule, Scoresbysund, and Qaqortoq, also differs from the previous two, by up to $4.6 \mathrm{~mm} /$ year. These differences, which are attributed to reference frame realization and from applying different models and/or different model options, highlights the need for an improved GPS observational paradigm in Greenland.

Gobinddass et al. (2009) provide a non-GPS estimate of the motion of the Thule DORIS beacon, and highlight the importance of addressing systematic errors in geodetic measurements so that accurate surface velocities may be obtained. Most recently, GPS-based studies have identified changing patterns of behaviour in Greenland (Jiang et al. 2010; Khan et al. 2010), with the authors suggesting that this is due to elastic rebound, severely complicating attempts to measure GIA. Despite this, the current Greenland GPS network (Fig. 1) together with improved GPS data processing and analysis methods, should help to provide meaningful constraints to models of GIA in Greenland.

\subsubsection{Antarctica}

The current array of ground-based GPS sites in Antarctica is shown in Fig. 2. Until recently, many of the GPS sites have been co-located with Antarctic science stations around the ice sheet perimeter. Important additional observations are provided by the Scientific Committee for Antarctic Research (SCAR) GPS epoch campaign (e.g., Dietrich et al. 2001) data collected starting in the early $1990 \mathrm{~s}$, and from the mid-1990 s from the WAGN, TAMDEF, VLNDEF and other networks (e.g., Tregoning et al. 2000; Zanutta et al. 2008). Recent advances have included the array of POLENET sites installed under the US programme starting 2007-8 and further international deployments are also due in the next years.

While data spanning long time periods have been collected at many of the campaign and continuous sites, many analysts are yet to publish results, although there are some 
exceptions. Donnellan and Luyendyk (2004) reported on vertical velocities in western Marie Byrd Land, with values up to $12.4 \mathrm{~mm} /$ year. It was suggested that these are consistent with GIA models of significant ice thinning in the eastern Ross Ice Shelf in the late Holocene. Raymond et al. (2004) reported on velocities determined using campaign data from two sites in the Northern Transantarctic Mountains. They found that they differed from uplift predictions based on ICE-3G and ICE-4G, but were consistent with an ice model which included deglaciation right up to the late Holocene. Dietrich et al. (2004) determined GPS velocities for much of coastal Antarctica and estimated that their vertical velocities were accurate to only 5-6 mm/year at that time. Since all but one of their velocities were substantially smaller than this they did not attempt to interpret the results further. Only the $9.5 \mathrm{~mm}$ /year uplift at O'Higgins, located on the northern tip of the Antarctic Peninsula, was regarded as probably significant, noting that some GIA models tended to predict larger uplift rates in the southern peninsula, opposite to that observed. Fukuzaki et al. (2005) compared VLBI and GPS estimates of vertical motion at Syowa and O'Higgins and found inter-technique differences of the order of several millimetres per year. Ohzono et al. (2006) analysed all IGS station data from around Antarctica and concluded that none of the tested GIA models could successfully reproduce their estimates of vertical crustal movement. Comparison of GPS and VLBI rates at Syowa showed differences of $3 \mathrm{~mm} /$ year in the vertical component (compare with Fukuzaki et al. 2005). Their analysis confirmed the anomalously large uplift rate on the northern Antarctic Peninsula, and they suggested that this may be due to ongoing ice mass loss in this region. Makinen et al. (2007) reviewed the status of absolute gravity data collection in Antarctica and compared available rates with vertical velocities from GPS, DORIS and VLBI data, where available. Results showed substantial differences and highlighted the potential value for absolute gravity to validate different space geodetic solutions.

Two recent studies offer perhaps more robust results since they are based on homogeneously reprocessed time series and a global reference frame (ITRF2005, see Sect. 4), although as we explain in this paper, even these are not free from systematic error. Rulke et al. (2008) showed vertical velocities from 11 sites around the coast of Antarctica, with additional campaign sites shown in Dietrich and Rülke (2008). Compared to those predicted by Ivins and James (2005) there was general qualitative agreement, although a quantitative analysis was not presented. Larger disagreements included those at Dumont D'Urville and McMurdo where subsidence of a few $\mathrm{mm}$ /year was observed, although uplift is predicted by Ivins and James (2005). Based on another homogeneous reprocessing, Amalvict et al. (2009) compared GPS and DORIS at Dumont D'Urville and found sub$\mathrm{mm} /$ year agreement between the two techniques over their entire data spans, but more substantial differences over shorter periods. The mean vertical velocity of $\sim 0.3 \mathrm{~mm} /$ year was much smaller than the $2.5 \mathrm{~mm} /$ year predicted by Ivins and James (2005). They attributed the difference to possible elastic effects due to increased accumulation of snow and/or a lack of knowledge of the precise local ice history. On the other hand, trends from absolute gravity measurements were in closer agreement with the model. A further paper provides the most spatially comprehensive assessment of West Antarctic GIA, with Bevis et al. (2009) reporting GPS-based uplift rates based on a combination of continuous and their own campaign sites. They suggested that observed GIA rates in this region are substantially smaller than presently available GIA models would suggest. The spatial pattern of the observed uplift is also more complex. Since the data for many of their sites were from short campaigns over 3-4 years, their error bars remain higher than desirable although their major conclusions appear robust. 
It is clear that GIA-related surface displacement observation and analysis around Antarctica, as with Greenland, is yet to reach maturity and further developments are required. Further site deployments are required, but substantial parallel developments in observation analysis and reference frame theory are required to enable these results to fully realise their potential. In the following sections we highlight the key areas of need, starting with GPS observation models.

\section{GPS Observation-Level Models and Systematic Biases}

\subsection{Introduction}

The accepted norm in obtaining 3-d GPS site velocities is to follow a two step process, first site coordinates (together with many other parameters) are estimated over a defined period (usually $24 \mathrm{~h}$ or less). Parameter estimation and model corrections applied during this process are often called "observation level" and need to be accurate over the observation period. On the other hand the effects of processes that affect site position on longer timescales such as GIA, tectonic deformation and seasonal effects are neglected during this step. The second step is to collate these snapshots of the Earth's shape and estimate site velocities (see Sect. 4). The accuracy of site velocities is therefore dependent on two intimately related stages of modelling, at the observation level and at the velocity estimation level.

Observation level biases affect 3-d velocities computed from GPS observations in one of two ways. First, slowly varying systematic errors may map into quasi-secular bias in site positions. One example of this is provided by Ge et al. (2005) who demonstrated satellite-specific antenna phase centre offsets from the satellite centre of mass. As the design of in-orbit GPS satellites has evolved over time, neglecting this bias resulted in a quasi-secular variation in GPS scale. Furthermore, Cardellach et al. (2007) showed that satellite antenna-model errors introduce a global GPS network distortion that result in radial velocity errors at the $1-2 \mathrm{~mm} /$ year level. As discussed below, models of signals with long periods, such as from satellite modelling or propagation effects are not yet robust enough for geodetic GPS analysis software and errors of this type may still be present in state-of-the-art GPS analysis. Secondly, unmodelled sub-daily signals may propagate into longer-periods (e.g., Penna et al. 2007; Yuan et al. 2009) biasing and adding noise to geophysical estimates. Propagation of such signal depends on the nature of the unmodelled signal and also the GPS design matrix, and hence is sensitive to site location, satellite geometry and parameterisation, resulting in potentially complex propagation (Stewart et al. 2005). Tidal signals have been studied best to date, with tidal signals propagating to annual, semi-annual and fortnightly periods for example (Penna et al. 2007). King et al. (2008) examined the actual sub-daily coordinate spectra of multiyear solutions spanning 2000-2007 after modelling relatively well defined sub-daily periodic signals such as solid Earth tides and ocean tide loading displacements. They found signals at periods corresponding to $\mathrm{K} 1, \mathrm{~K} 2$ and $\mathrm{S} 1$ (amongst others), with amplitudes typically a few millimetres. At some sites, however, amplitudes exceeded $10 \mathrm{~mm}$. They exhibited substantial temporal variability. The origins of these sub-daily signals were not unambiguously identified by King et al. (2008), who suggested local signal (e.g., multipath), propagation (e.g., higher order ionosphere) and orbit (e.g., solar radiation pressure) mismodelling. More recently, Yuan et al. (2009) showed that changing the modelled K2 ocean tide loading displacement by a few millimetres gave a velocity bias of 
up to $1.0 \mathrm{~mm} /$ year (taken over the period 2000-2007) for sites in Hong Kong. Accurate observation-level models are therefore critical to obtaining accurate and precise site velocities such as are needed to constrain GIA models.

Comparison of GPS time series with independent models (Dong et al. 2002) or GRACE data (Davis et al. 2004; King et al. 2006; van Dam et al. 2007) have shown generally poor agreement. Errors in the GPS time series are suspected to be dominant and Tregoning et al. (2009) have recently shown improved, but far from perfect, agreement based on a homogeneous reprocessing of GPS data using state-of-the-art observation models. Indeed subtracting GRACE estimates of surface loading displacement from their GPS time series resulted in an increase in variance at nearly $50 \%$ of the sites. There is clearly need for further development, and we discuss the present-day knowledge of these signals by following the various contributions to the GPS signal from the satellite to the receiver.

\subsection{Satellite Orbit Modelling}

The consistency between International GNSS Service (IGS, Dow et al. 2009) analysis centre final GPS orbit products is presently at the level of 0.01-0.02 $\mathrm{m}$. However, because analysis centres use similar or identical standards, this may only be regarded as a measure of internal precision, and not an assessment of satellite positioning accuracy. Inaccuracy/imprecision in orbit computation will degrade GPS-determined velocities and their uncertainties.

In recent years, several authors have indicated that there are some systematic errors in the combined orbit of the IGS. Improvement in orbit accuracy is essential because, according to the rule of thumb of Baueršima (1983), an orbital error $\Delta X$ on a network with an extension $l$ (in $\mathrm{km}$ ) has an effect on baseline lengths $\Delta l$ of $l / 25000 \mathrm{~km} * \Delta X$. This means an orbital error of $2 \mathrm{~cm}$ impacts on a network with an extension of $1250 \mathrm{~km}$ with an impact of less than $1 \mathrm{~mm}$. Even if this value is too pessimistic for permanent network solutions (Zielinski 1988) many geophysical GPS networks are larger today and hence there is still value in this rule of thumb. Below we discuss a number of issues relating to orbit determination and modelling.

Ray et al. (2008) examined the dominant frequencies in the weekly combined coordinate time series of the IGS network and detected significant peaks for a period of 351.2 days which corresponds closely to the draconitic year for a GPS satellite (see Beutler et al. 1994). This period is related to the position of the Sun with respect to the GPS satellite constellation. So both station related effects (e.g., multipath) or orbit modelling deficiencies may very likely cause this phenomenon. Ostini et al. (2007) demonstrated that there are regional correlations in amplitude and phase between these periodic functions detectable in the coordinate time series. This implies that at least a part of these periodic components are very likely caused by orbit modelling deficiencies [see also Tregoning and Watson (2009) and King and Watson (2010)].

Slabinski (2006) analyzed the discontinuities of the GPS orbits at the day boundaries of the IGS final orbits and has found non-random behaviour. Further investigations, e.g., in Griffiths and Ray (2008) have confirmed these results, with a fourteen day period particularly prominent. Flohrer (2008) analyzed these systematics in the orbit discontinuities and have found a correlation with the orbital plane of the satellites and the position of the Sun with respect to this plane.

SLR is a completely independent space geodetic technology and is therefore well suited for validation of GNSS orbits. In contrast to GLONASS where all satellites are equipped with SLR reflectors, only two GPS satellites (one of them was decommissioned in March 2009) carry reflectors to allow these comparisons. Both satellites are of the old Block IIA 
type whereas most of the GPS constellation now consists of newer generations of satellites. For that reason the interpretation of systematic effects in the differences of SLR measurements with respect to estimated GPS orbits-as they are shown in Fig. 4 (Urschl et al. 2007) - is not easy. It cannot be distinguished between general or type-specific orbit modelling deficiencies.

Nevertheless, the position of the Sun with respect to the orbital plane was identified as an important component of the difference. Using the latest updated coefficients of the empirical radiation pressure model proposed by Springer et al. (1999) has improved the situation.

In this context it is noticeable that the use of the empirical model did improve the quality of predicted orbits for GPS (in particular for the Block IIA satellites).

It has been shown in Dach et al. (2008) that systematic effects from orbital mismodelling may translate the origin of the global terrestrial reference frame when the orbit parameters are computed together with the site coordinates. If the orbits are introduced as known - but with a bias - a systematic deformation of the observation network geometry may still occur. In particular, systematic biases in the orbits may introduce periodic variations in the site coordinates that may be misinterpreted as geophysical phenomena and bias site velocities.

GPS orbit modelling clearly requires further refinement to reduce orbit errors to negligible levels. From the afore-mentioned studies the following steps toward improving the situation may be identified:
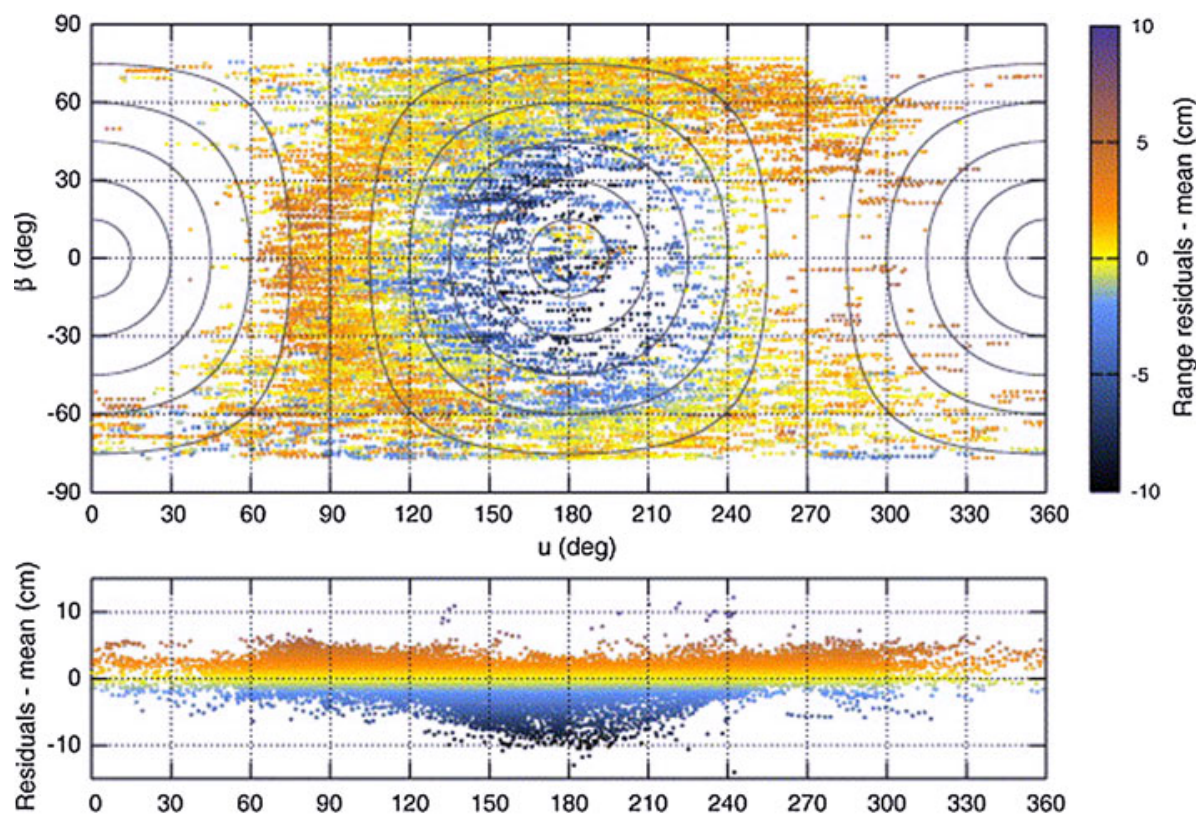

Fig. 4 Colour-coded SLR range residuals $(\mathrm{cm})$ minus mean value derived from CODE final orbits for the GPS satellites PRN G05 and G06 in the $(u, \beta)$-coordinate system; bottom: projection onto $u$-axis; circles represent phase angle $E, 15^{\circ}$ spacing, $0^{\circ}$ at centre, $180^{\circ}$ at edges. Reprinted from Advances in Space Research, Vol 39(10), Urschl C, Beutler G, Gurtner W, Hugentobler U, Schaer S, Contribution of SLR to tracking data to GNSS orbit determination, 1515-1523, Copyright (2007), with permission from Elsevier 
- An improved physical radiation pressure model for the satellites is required (e.g., Ziebart et al. 2005);

- Earth albedo effects need to be considered;

- The satellite antenna phase centre model needs to be improved because currently only empirical models with nadir-dependency are used (Schmid et al. 2005; Wübbena and Schmitz 2008);

- Sub-daily components of polar motion models must also be investigated as they represent a potential source of systematic effects in the discontinuities in satellite orbits at day boundaries.

The use of different types of satellites and satellites from different systems with different orbit characteristics (e.g., combining GPS and GLONASS, in future also Galileo, Dach et al. 2009) may help to distinguish between the phenomena that are Earth/site related or related to the modelling of the satellite behaviour itself. To demonstrate the impact of the different components and to detect model deficiencies, long time series of data (several years) need to be processed in a homogeneous way.

\subsection{Satellite and Receiver Antenna Phase Centre Models}

Raw GPS measurements refer to the actual phase centres of the satellite and receiver antennas. As the phase centres vary with the observation direction, these antenna phase centre variations (PCVs) have to be corrected in high precision GPS application. Receiver antenna PCVs can be determined by relative field calibrations (Mader 1999), by absolute robot calibrations (Menge et al. 1998) and by anechoic chamber measurements (Görres et al. 2006). Absolute and anechoic calibration methods agree within $\sim 1 \mathrm{~mm}$ (Görres et al. 2006). Schmid and Rothacher (2003) showed that absolute satellite antenna PCVs can be estimated within global GPS solutions. The satellite antenna phase centre model currently used by the IGS, known as igs05.atx, was determined from $\sim 11$ years of reprocessed GPS data (Schmid et al. 2007) with a precision of a few tenths of a mm for the PCVs and a few millimetres for the vertical antenna offsets. The receiver antenna part of igs 05 . atx consists of absolute robot calibrations as well as converted field calibrations. However, the converted calibrations have two major disadvantages: (1) there are no azimuth-dependent PCV values (i.e., they are presently only zenith-dependent); and (2) PCV values below $10^{\circ}$ elevation are unavailable meaning that the use of low-elevation satellite data is not possible at sites with these antenna types, which are critical to improve vertical coordinate estimates.

For 193 out of the current $\sim 400$ IGS sites, robot calibrations are available and 80 sites have converted calibrations. For 52 sites the PCVs were copied from antennas which are assumed to be constructed in the same way. For several antenna/radome combinations no calibrations are available at all. Therefore, the effect of the radome is ignored for these 88 sites. 46 out of these 88 sites are equipped with an uncalibratable radome type (DOME, ENCL, JPLA). To study the impact of radome calibrations on global GPS solutions, Steigenberger et al. (2009b) compared terrestrial reference frames (TRFs) computed with different phase centre models, and found velocities of most sites change by up to $\sim 2 \mathrm{~mm}$ / year when ignoring the antennas with radome calibrations, although several sites showed vertical velocity changes of up to $\pm 5 \mathrm{~mm} /$ year. This is summarized in Fig. 5, where horizontal and vertical position and velocity TRF residuals are shown for solutions with and without radome calibrations (solutions IGS05 and IGS05woR of Steigenberger et al. 

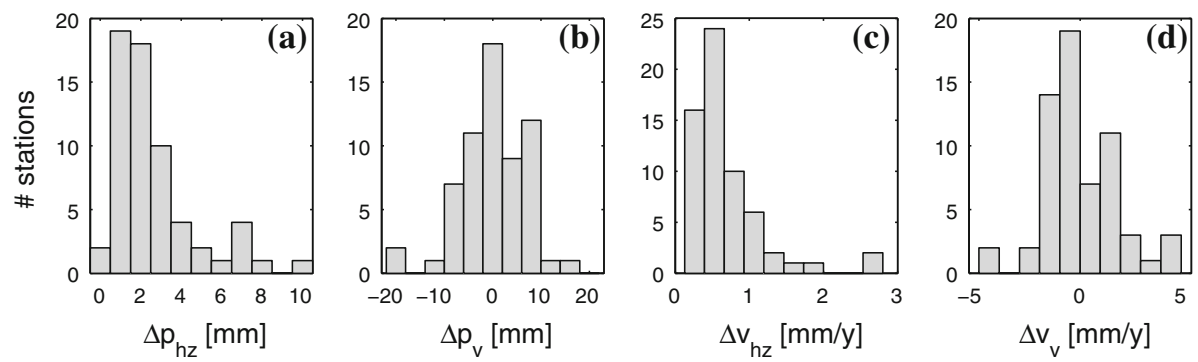

Fig. 5 Residuals of a 14-parameter similarity transformation between TRFs computed with and without radome calibrations: a horizontal position residuals; $\mathbf{b}$ vertical position residuals; $\mathbf{c}$ horizontal velocity residuals; d vertical velocity residuals

(2009b)). This example clearly shows the necessity of proper antenna calibrations for longterm studies of site motions.

To minimize such effects the following advances are required:

- First, uncalibratable radome types should be removed or replaced as soon as possible;

- Second, individual antenna calibrations should become routine;

- Third, the satellite antenna offsets of igs05.atx needs to be replaced by estimates based on the IGS reprocessing effort (Steigenberger et al. 2008). This replacement will solve two problems of the current igs05.atx: (1) some offset estimates are based on short periods of data, and (2) for satellites launched after the release of igs05.atx, only mean values per satellite block are given. Satellite offset errors produce potentially large velocity biases (Cardellach et al. 2007);

- Fourth, all missing antenna/radome calibrations (including those of previously active sites) should be added to this revised IGS antenna phase centre model, and converted calibrations should be replaced by robot calibrations;

- Fifth, other observation model updates, such as those discussed in this paper, will significantly affect the estimated site positions and velocities; a complete reprocessing will be necessary to generate a new terrestrial reference frame that can consistently be used together with the phase centre model.

State-of-the-art observation models should be used when estimating the satellite offsets and phase centre variations. For future navigation systems (such as the European Galileo System) a pre-flight calibration of the transmitter antennas should also be considered.

\subsection{Higher Order Ionospheric Terms}

The best way to account for the effects of the ionospheric delay is by means of the so called ionospheric free combination of dual-frequency observables. This combination cancels out the first order ionospheric dependence, about $99.9 \%$ of the total ionospheric effect. However the remaining higher order ionospheric terms, in particular the second order term (I2) that are also dependent on the Earth's magnetic field vector, can introduce noticeable effects, among other terms such as the geometric path bending (see the unratified updates to Chapter 9.4 of the IERS Conventions, http://tai.bipm.org/iers/convupdt/convupdt.htm). These effects can reach several centimetres in range at low latitude and during the maximum flux part of the solar cycle, and affect, at the centimetre level, estimates of GPS orbits, satellite clocks and the geocentre (Hernández-Pajares et al. 2007; Petrie et al. 
(a)

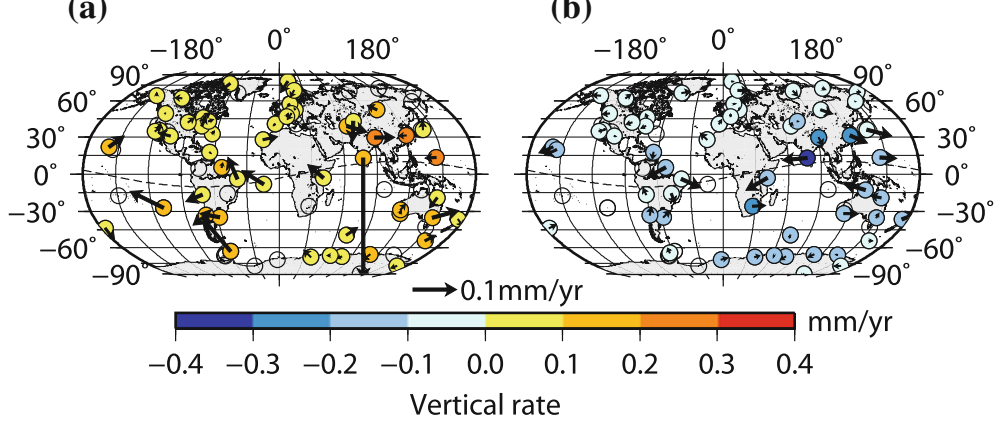

Fig. 6 Effect of modelling 2nd and 3rd order ionosphere terms on site velocities. a Velocity differences are computed over the period 1996-2000. b Velocity differences computed over the period 2001-2005 (N-IG). Arrows represent horizontal motion. T geomagnetic equator is shown as a dashed line. Sites shown have data spanning at least 4.5 years of the 5 year period, with a minimum of 2.5 years of data. Empty circles show sites processed which did not meet these criteria. Reproduced from Petrie et al. (2010b)

2010b). With regards to site coordinate time series, the I2 effect can create a significant bias (Kedar et al. 2003). Its size and error vector depend on the site geometry and corresponding relative $\mathrm{I} 2$ effect in range and can reach up to a few millimetres (HernándezPajares et al. 2007). The third order term is of less concern as it is at most of the order of a few millimetres of range error estimates (Fritsche et al. 2005).

For high latitude areas such as Greenland and Antarctica, higher order effects can affect coordinates at the millimetre level for I2. As shown in Fig. 6, Petrie et al. (2010b) demonstrated that neglecting higher order ionospheric terms can bias 3-d site velocities, with up to $\sim 0.4 \mathrm{~mm} /$ year biases appearing in the vertical component, after transforming to the ITRF, depending on the evolution of electron content throughout the solar cycle, and producing a maximum bias of up to a few millimetres in position after half a solar cycle, i.e. about six years. The sign of the vertical velocity bias is dependent on the sign of the slope of the total electron content over the period of observation. Since many GPS sites have been installed in regions of GIA since the last ionospheric maximum (2000-2002), not accounting for this term could produce a negative bias in computed velocities.

Other effects such as the geometric path bending and dTEC bending corrections (due to the electron content difference between the slightly different bent L1/L2 paths) are probably negligible at current GPS/reference frame precisions, following Petrie et al. (2010a), with a maximum estimated effect of few $\mathrm{mm}$ at low latitudes. However the overall higher order effects could be significantly higher during large ionospheric storms. These infrequent periods should be avoided in the data processing for long time series of GPS site coordinates. Whereas long period ionospheric variation may bias velocities, short-lived events will only introduce noise into geodetic time series. Such effects related to geomagnetic storms can also be observed in DORIS coordinate time series (Willis et al. 2005).

\subsection{Tropospheric Modelling Errors}

In the analysis of radio space geodetic techniques delays of the signals in the neutral atmosphere (mainly in the troposphere, but layers up to at least $80 \mathrm{~km}$ have to be considered) are usually modelled by a sum of hydrostatic and wet parts, and each of them is 
the product of the zenith (hydrostatic or wet) delay and the corresponding (hydrostatic or wet) mapping function (see, e.g., Davis et al. 1985). Whereas the zenith hydrostatic delay may be determined from the pressure at the site (Saastamoinen 1972; Davis et al. 1985) (from local measurements or from numerical weather models) and mapped with the hydrostatic mapping function to obtain the delay at a certain elevation angle, the zenith wet delay cannot be accurately modelled and is instead estimated in the least-squares adjustment with the wet mapping function as the corresponding partial derivative. In addition to the zenith wet delays, gradients are usually estimated in the analysis of space geodetic observations (e.g., Davis et al. 1993). This mainly affects horizontal site coordinates and does not affect vertical velocities at the sites (if consistently treated over the whole time span).

The most accurate mapping function globally available is, at present, the Vienna Mapping Function 1 (VMF1, Boehm et al. 2006b). Niell (2006) assessed the accuracy of VMF1 and other mapping functions by comparison with radiosonde data, and found that the accuracy of the hydrostatic VMF1 is about $3 \mathrm{~mm}$ at the poles and about $1 \mathrm{~mm}$ at the equator by considering height scatter. The height error due to the wet VMF1 is negligible at the poles (there is hardly any water vapour) but can be as large as $2 \mathrm{~mm}$ at the equator. However, the radiosonde data used by Niell (2006) for the comparison might have been assimilated in the numerical weather model used for the determination of VMF1. Thus, errors of VMF1 could be larger in some areas. If VMF1 and measured pressure values are not available, empirical functions are recommended to be used as replacement, i.e. the Global Mapping Function (GMF, Boehm et al. 2006a) and the Global Pressure and Temperature model (GPT, Boehm et al. 2007). Steigenberger et al. (2009a) compared these models and found that height errors of GMF/GPT with respect to VMF1 and zenith hydrostatic delays (ZHD) derived from data of the European Centre for Medium-Range Weather Forecasts (ECMWF) can be as large as several $\mathrm{mm}$ in polar regions. Tregoning and Watson (2009) recommend using the time-varying VMF1 and zenith hydrostatic delays from numerical weather models because of the lower noise at a range of frequencies compared with solutions using empirical models (GMF/GPT), in particular when tidal and non-tidal atmospheric loading corrections are applied in GPS analysis. Figure 7 shows the trends of the differences between the hydrostatic GMF and the gridded VMF1 data (at the orographic surface and all nodes of the VMF1) for Antarctica over five years from 2003.0 to 2008.0. Results are expressed in terms of height velocity with the rule of thumb that the height error is $1 / 5^{\text {th }}$ of the a priori delay error at $5^{\circ}$ elevation (Boehm et al. 2006b). Results use ZHDs derived from 6-hourly numerical weather data, and Fig. 8 shows the trends of the differences between GPT and numerical weather model data for Antarctica over the same period. The same rule of thumb is used and differences are mapped with the gridded VMF1 data.

In both cases, vertical velocities computed over this period are biased by values greater than $\pm 0.25 \mathrm{~mm} /$ year in various regions. Both simulations confirm the importance of the time-varying VMF1 and hydrostatic zenith delays for the estimation of height velocities, because empirical models such as GMF and GPT cannot account for year-to-year differences.

We note that numerical weather models in areas of GIA interest (in particular Antarctica) are not as accurate as in other parts on Earth because the amount of observational data is geographically limited. This is also confirmed by comparisons between data from ECMWF and NCEP for atmospheric loading studies (see Table 1). However, if the topography is correctly taken into account, we assume that the agreement between mapping functions derived from 6-hourly ECMWF and NCEP data would be considerably 


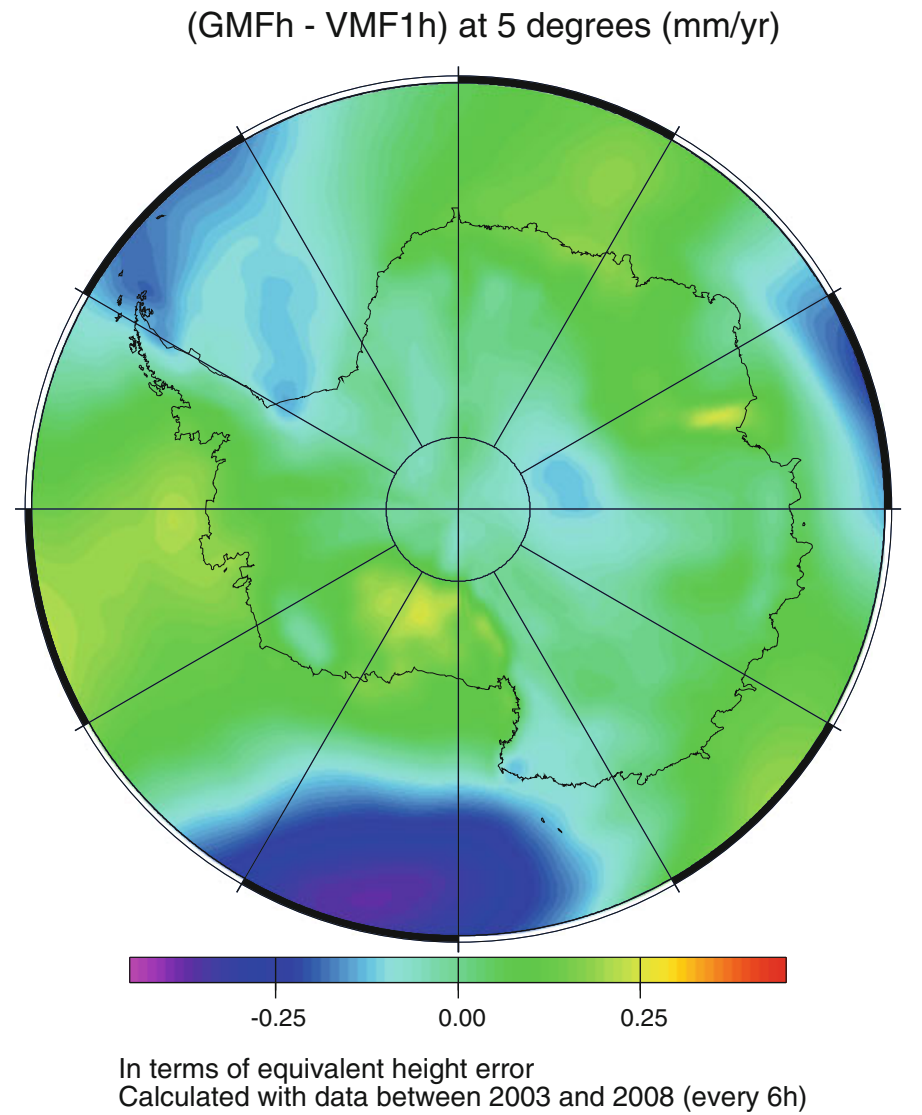

Fig. 7 Simulated height velocity differences in $\mathrm{mm} / \mathrm{year}$ determined from differences between the hydrostatic GMF and VMF1 over five years from 2003 to 2008

better than the agreement with empirical models. To validate this assumption, further tests are required.

\subsection{Atmospheric Loading Displacements}

Variations in the horizontal distribution of atmospheric mass induce displacements of the Earth's surface. The interaction between the atmosphere and the Earth is through pressure loading at the surface and, particularly at longer wavelengths, through the gravitational attraction of the atmospheric mass. The displacement of the surface is primarily vertical (horizontal displacements are about $1 / 3$ the magnitude of the vertical displacements), and there is a change in the acceleration of gravity at the displaced surface. In the absence of large secular pressure changes, atmospheric loading displacements will represent a noise signal in GPS velocity estimates, although sub-daily atmospheric loading may represent an important exception as discussed below.

The largest pressure variations are associated with the passage of synoptic scale pressure systems. Theoretical estimates of the amplitude of the surface displacement using either a global convolution sum of surface pressure with an elastic Green's function 


\section{(ZHD-GPT - VZHD) at 5 degrees ( $\mathrm{mm} / \mathrm{yr}$ )}

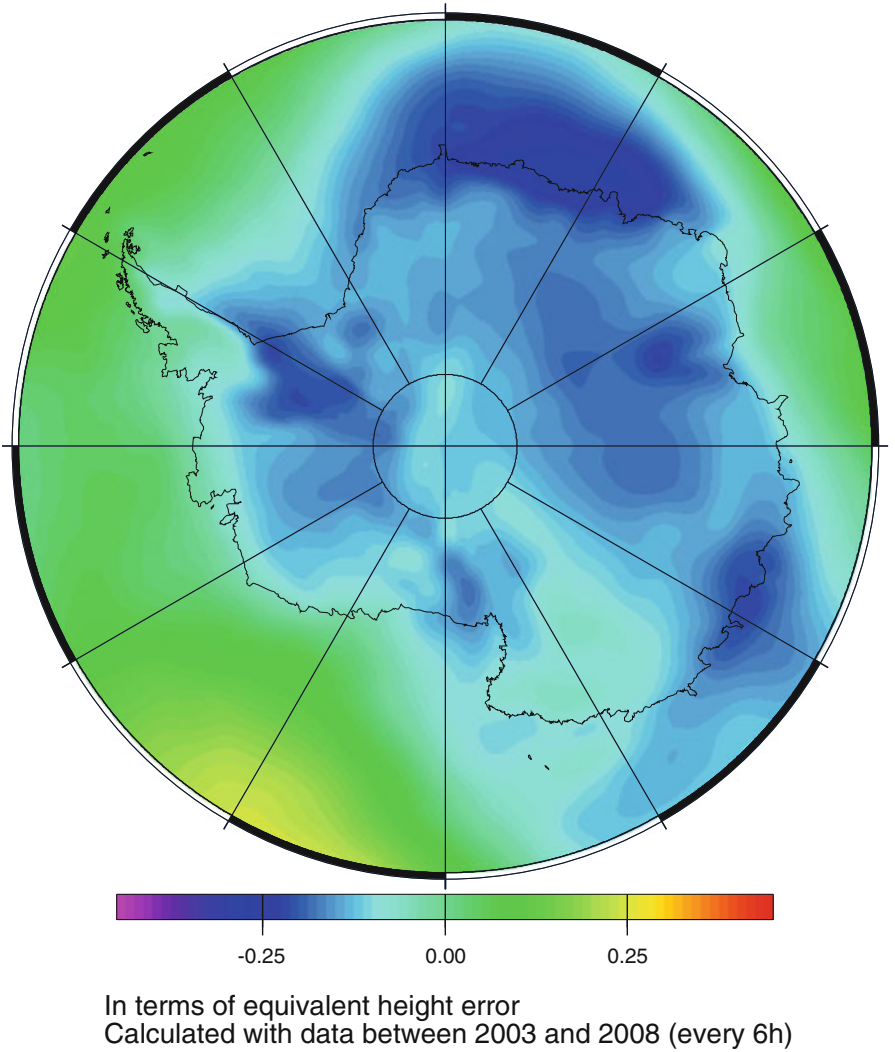

Fig. 8 Simulated height velocity differences in $\mathrm{mm} /$ year determined from differences between a priori hydrostatic delays from GPT and 6-hourly numerical weather model data over 5 years from 2003 to 2008

Table 1 Root Mean Square (RMS) error of differences in loading displacement time series computed on a $2.5^{\circ} \times 2.5^{\circ}$ global grid for one year

\begin{tabular}{llll}
\hline Model variant & $\begin{array}{l}\text { Max. RMS } \\
(\mathrm{mm})\end{array}$ & $\begin{array}{l}\text { Mean RMS } \\
(\mathrm{mm})\end{array}$ & $\begin{array}{l}\text { Geographic region affected by model } \\
\text { difference }\end{array}$ \\
\hline $\begin{array}{l}\text { Land-ocean mask } \\
\text { Pressure effects } \\
\text { ECMWF vs. NCEPR }\end{array}$ & 2.6 & 0.4 & Near enclosed seas and areas in Antarctica \\
$\begin{array}{ll}\text { Reference pressure } \\
\text { Atmospheric tides }\end{array}$ & 0.0 & 0.2 & $\begin{array}{l}\text { Antarctica and regions of large topographic } \\
\text { variability }\end{array}$ \\
$\begin{array}{l}\text { Green's functions } \\
\text { Conv. sum versus Spherical } \\
\text { Harmonic }\end{array}$ & 0.8 & 0.0 & $\begin{array}{l}\text { Adds a bias to different products } \\
\text { Equatorial to Mid-Latitudes }\end{array}$ \\
\hline
\end{tabular}

ECMWF is using pressure fields from the European Centre for Medium-Range Weather Forecasts and NCEPR is using fields from the National Center for Environmental Prediction Reanalysis 
(Farrell 1972) or a summation of the spherical harmonic representation of the pressure field with load Love numbers, indicates that the predicted surface displacement is often large enough to be detected by current geodetic techniques. In fact, the effects of atmospheric pressure loading have been detected in GPS coordinate time series (van Dam and Herring 1994; Dong et al. 2002; Scherneck et al. 2003; Zerbini et al. 2004), VLBI coordinates (Rabbel and Schuh 1986; Manabe et al. 1991; MacMillan and Gipson 1994; van Dam and Herring 1994; Petrov and Boy 2004) and SLR (Bock et al. 2005).

Atmospheric loading displacement values may be computed based on one of several computational methodologies and different input data sets, and at present these are held to be equally valid in most cases. However, different choices result in slight differences in the calculated surface displacements. Because of a general lack of documentation in most cases, a potential user comparing different products might not be able to determine which parameters are driving the observed differences between loading time series provided by the different groups.

A thorough analysis of the differences between the atmospheric loading effects calculated by different groups, has been presented in van Dam (in press). They examined the effects of five variations in the loading computations : (1) different land-ocean masks, (2) different pressure data sets (European Centre for Medium-Range Weather Forecasts versus the National Center for Environmental Prediction Reanalysis data), (3) different reference pressure, (4) different Green's functions, and (5) loading Love numbers or Green's functions. To summarise the differences, loading displacements were computed on a 6 hourly basis for 1 year on a $2.5^{\circ} \times 2.5^{\circ}$ global grid. The RMS of the differences was computed for each point and the maximum and average RMS differences are shown in Table 1.

If inland seas and ice-shelves are defined as land or as ocean in a scheme to generate loading effects, differences can arise in the estimates of the surface displacement in these regions. Table 1 shows that the effect is regional and it can be significant. Depending on the location of one's sites of interest, a user should compare different solutions at sites near the enclosed bays to determine which product is better suited. Differences between predicted loading effects, which are dependent on the pressure data set used, are largest in Antarctica where in situ data are lacking. Otherwise, the choice of input pressure data set used will have little effect on the predicted loading.

Elastic Green's functions can be derived from different Earth models. From Table 1, it is clear the choice of Green's functions is insignificant. Finally, the difference between computing the loading using spherical harmonics (load Love numbers) or using global grids (Green's functions) can introduce maximum differences of up to $1 \mathrm{~mm}$ in site coordinate time series, however the scatter is well below $1 \mathrm{~mm}$. In the absence of a large secular term in atmospheric pressure fields (small ones are evident in some locations over several decades, including Antarctica (Heil 2006)), errors in modelling long-period atmospheric pressure loading displacements therefore introduce noise into geodetic time series, thereby decreasing velocity precision.

Diurnal and semi-diurnal atmospheric tides are included in surface pressure data. These tides have been found to be in error (in phase and amplitude) when compared to in situ data in some locations (Ray 2001). The S2 signal is only partially sampled in 6 h products and hence is particularly susceptible to error. As a result, some groups chose to remove the erroneous tides from the input surface pressure data. Tregoning and Watson (2009) showed the effect of modelling S1 and S2 atmospheric tidal loading displacements. Homogeneously reprocessed site time series with observation-level modelling of these terms showed substantially different coloured noise to those with the terms unmodelled as well as reduced signal at the GPS draconitic year and its harmonics when S1 and S2 atmospheric 
loading displacements were modelled. Ambiguity fixing was also shown to substantially reduce the anomalous harmonics. The importance of these sub-daily terms to site velocities is yet to be reported.

Atmospheric loading displacements represent only one of several environmental loading terms. Hydrological (including groundwater and snow) and non-tidal ocean mass variability also affect geodetic time series. However, in regions of GIA these will normally be of small amplitude (see Dong et al. 2002) and with a poorly defined, but probably small, secular component. As mentioned previously, a more important signal, particularly in Greenland and some regions of Antarctica, is due to elastic rebound due to contemporaneous local ice loading/unloading (e.g., Khan et al. 2007). These tend to be highly localised signals, with amplitudes reaching several $\mathrm{mm} / \mathrm{year}$, and rigorous global models are required.

\subsection{Solid Earth Tides}

Tidal deformation models as specified in the IERS 2003 Conventions (McCarthy and Petit 2004) are believed to be accurate to $1 \mathrm{~mm}$ globally (Mathews et al. 1997). Computing the tidal deformation for a particular time and location requires knowledge of two components. First, up-to-date ephemerides (primarily of the Moon and the Sun) are needed and may be regarded as error free in present-day models. Second, the Earth's response to the tidal potential must be modelled. This is a critical step assuming perfect knowledge of dimensionless Love (and Shida) numbers. The most recent numbers are comprised of multiple parameters in order to consider site latitude dependence, and frequency dependence at the diurnal band due to the free core nutation (Mathews et al. 1995). Moreover, these numbers include contributions from the Earth's ellipticity and the de Coriolis and centrifugal forces due to Earth rotation obtained from a perturbation method (Buffett et al. 1993). Effects arising due to variations in length of day are included, as well as those produced by mantle anelasticity. The latter effect is responsible for the Love numbers being complex.

One potentially significant effect that is not yet included in the conventional model relates to lateral variations in Earth structure. Differences between Earth tides modelled using a 3-d Earth model compared to a 1-d model have recently been reported (Latychev et al. 2009), with variations up to $\sim 1 \mathrm{~mm}$ in the radial component of the semi-diurnal band. When considering regions of GIA, the model of Latychev et al. (2009) suggests that the effect may be largest in West Antarctica and North America. If verified, this, along with uncertainties in modelled anelasticity (Mathews et al. 1997), is the dominant weakness in solid Earth tide models at present; any error will propagate into GPS coordinate time series (Penna et al. 2007). A comparison of solid Earth tidal site displacement models with observed values is complicated by ocean tide (and to a smaller extent atmospheric tide) loading displacement effects (Wahr 1995), discussed further below.

In order to determine the impact of mismodelled solid Earth tidal site displacements on velocity determination, we considered eight locations in Antarctica, each with permanent GPS receivers (see Table 2 and Fig. 2). Since solid Earth tides are latitude dependent, these equally apply to northern hemisphere sites at high latitudes. Following Blewitt and Lavallee (2002), we simulated frequency-dependent and out-of-phase terms of the tidal displacement calculations (Mathews et al. 1997) for the eight sites with a temporal resolution of $3 \mathrm{~h}$, and a time span of 2.5 years since the year 2009 and only consider the radial displacement. 
Table 2 Estimates of vertical site coordinate trends (in 2.5 year windows from 2009) and their standard deviations due to uncertainties in the solid Earth tide model for eight long-running IGS sites around the coast of Antarctica

\begin{tabular}{lccccc}
\hline Site Code & Longitude $\left(^{\circ}\right)$ & Latitude $\left(^{\circ}\right)$ & Height $(\mathrm{m})$ & Trend $(\mathrm{mm} /$ year $)$ & SD $(\mathrm{mm} /$ year $)$ \\
\hline OHI3 & -57.9013 & -63.3211 & 33.15 & 0.076 & 0.009 \\
VESL & -2.8418 & -71.6738 & 862.40 & 0.077 & 0.010 \\
SYOG & 39.5837 & -69.0070 & 50.09 & 0.077 & 0.010 \\
MAW1 & 62.8707 & -67.6048 & 59.18 & 0.077 & 0.010 \\
DAV1 & 77.9726 & -68.5773 & 44.50 & 0.077 & 0.010 \\
CAS1 & 110.5197 & -66.2834 & 22.55 & 0.077 & 0.009 \\
DUM1 & 140.0019 & -66.6651 & -1.38 & 0.077 & 0.010 \\
MCM4 & 166.8893 & -77.8383 & 98.02 & 0.079 & 0.011 \\
\hline
\end{tabular}

Since GPS site coordinates are only estimated once per day, and ignoring propagation of sub-daily tidal signals, we filtered the tidal displacement (frequency-dependent and out-ofphase terms) to a single value per day for each site. Using these values, the velocity of the radial tidal displacement was estimated for each site (see Table 2). We conclude that the present model of solid Earth tides by Mathews et al. (1997) is sufficiently precise for an accurate determination of velocities in Antarctica (to better than $0.1 \mathrm{~mm} / \mathrm{year}$ ), if the time span is larger than 2.5 years, and ignoring propagation of sub-daily tidal signals as discussed below. If the time span is increased ( $>18.6$ years), the trend should become zero, but if propagation occurs to longer periods and with sufficient amplitude, as discussed below, then substantial bias and noise may be introduced (e.g., Watson et al. 2006).

\subsection{Ocean Tide Loading Displacement Corrections}

Geodetic measurements are sensitive to periodic ocean tide loading (OTL) displacement and this displacement must be modelled in GPS, VLBI, SLR and DORIS analyses so that it can be removed. Unmodelled sub-daily OTL displacements propagate into coordinates estimated from GPS, VLBI, SLR and DORIS analyses and degrade the solution. Since GPS is more widely used than VLBI and SLR to constrain GIA models, removing this signal in GPS data analysis is particularly important. In GPS time series derived from $24 \mathrm{~h}$ batch estimates (as typically used in geodetic GPS analyses) unmodelled sub-daily tide signals propagate to produce long-period spurious signals, whose amplitude, phase and period are dependent on the harmonic's period, amplitude, phase lag, the satellite orbital repeat period and the site location (Stewart et al. 2005). These suggestions were confirmed using real data by Penna et al. (2007), with 13.66 and 14.8 day (beating together to produce a semiannual effect) and 183 day spurious signals arising from the dominant M2 and S2 harmonics, respectively. They also identified that for GPS coordinates estimated using $24 \mathrm{~h}$ batches, unmodelled East and North displacements propagate into the height component with admittances of up to $100 \%$, whilst unmodelled height displacements propagate with a much smaller admittance, typically around $10 \%$. Such OTL-induced spurious signals will degrade or bias vertical rate estimates.

The OTL displacement may be expressed as a sum of an infinite number of periodic signals. The frequencies of these periodic signals are taken from the tidal potential and are called harmonics. At a given location, the displacement per harmonic is represented as an amplitude and (usually Greenwich) phase lag, which enable the displacement at any instant 
in time to be predicted per harmonic, with the total displacement obtained by simply summing the displacement from each harmonic considered. Typically geodetic analyses have followed the IERS 2003 Conventions (McCarthy and Petit 2004) that recommend correcting for the 11 principal harmonics (M2, S2, N2, K2, K1, O1, P1, Q1, Mf, Mm and Ssa) which make up approximately $95 \%$ of the tidal potential, and also applying nodal corrections to account for nearby lunar companion harmonics with frequencies that differ from the main harmonic by only 1 cycle every 18.61 years. The unratified updates to the IERS conventions (http://tai.bipm.org/iers/convupdt/convupdt.html) however recommend correcting geodetic measurements using the 'hardisp' routine (based on the SPOTL suite of programs of Agnew (1996)), in which the amplitudes and phase-lags of the 11 principal harmonics are expanded to 342 harmonics by spline interpolation of the tidal admittance (Munk and Cartwright 1966). This represents the tidal potential to an accuracy of around $99 \%$.

At the site of interest, the OTL displacement amplitude and phase lag per harmonic are computed by convolving a global model (or "map") of the ocean tides with an elastic Earth model, using a loading Green's function (the effect of the ignored anelasticity of the Earth is around $0.1-1 \%$ for displacement). Penna et al. (2008) compared OTL height displacements computed with three different OTL software packages, namely CARGA (Bos and Baker 2005), SPOTL (Agnew 1996; Agnew 1997) and OLFG/OLMPP (Scherneck 1991), and considered the usually dominant M2 harmonic with a range of recent ocean tide models input. Agreements between the software packages were better than 1-2 mm everywhere and often better than $0.2-0.5 \mathrm{~mm}$, including sites both inland and adjacent to complicated coastlines and shallow seas.

To demonstrate the sensitivity of OTL displacement to the ocean tide model considered (and thus the quality of the ocean tide models themselves), OTL height displacement amplitudes and phase lags were computed for a global 0.25 degree grid using the SPOTL software for five recent ocean tide models, namely CSR4.0 (Eanes and Bettadpur 1996), FES2004 (Lefevre et al. 2002), GOT00.2 (Ray 1999), NAO.99b (Matsumoto et al. 2000) and TPXO6.2 (Egbert and Erofeeva 2002), for the M2, S2, O1 and K1 harmonics. These update the comparisons of Penna et al. (2007). The inter-model agreement is shown in Fig. 9, in the form of the RMS of their vector differences from the mean per grid point, and it can be seen that there is sub-mm agreement across most locations within the $\pm 66^{\circ}$ TOPEX/Poseidon latitude coverage limits. However, this is not true in regions near shallow seas (e.g., Indonesia) and outside the TOPEX/Poseidon coverage limits such as close to Greenland and in Antarctica, where the accuracy of the ocean tide models remains the limiting factor in OTL displacement calculations (Penna et al. 2008). Therefore there is not yet a single model that has been demonstrated as suitable for all regions of the world (Bos and Baker 2005; Penna et al. 2008), despite the IERS 2003 conventions recommending the blanket use of GOT00.2 or FES99 (Lefevre et al. 2002), and their unratified updates suggesting to use FES2004 or TPXO6.2. At present, the most appropriate geodetic analysis strategy is to apply OTL displacement values from different models dependent on the site's location, including the consideration of regional ocean tide models.

Until modelled OTL displacement amplitudes and phase lags are accurate everywhere to $\sim 0.1 \mathrm{~mm}$ such that the spurious signals are undetectable, aside from model improvement and extending the time series length, the most feasible mitigation method is to estimate a periodic term in the velocity estimation. However, this incorrectly assumes time-constant model errors (King et al. 2008) that will degrade the velocity estimation precision (Blewitt and Lavallee 2002), and hence the community is still encouraged to seek to improve the ocean tide models. 
M2

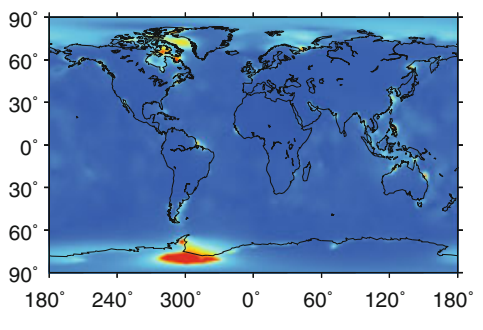

O1

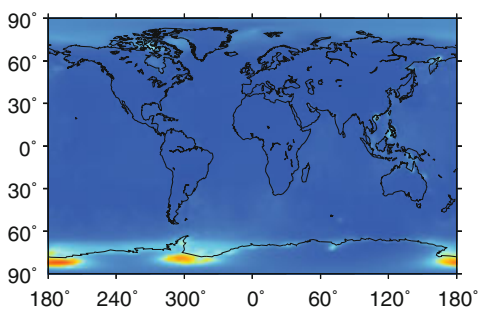

S2

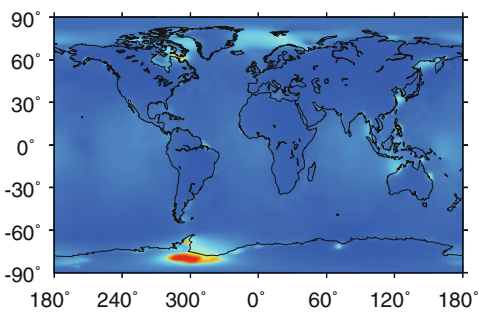

$\mathrm{K} 1$

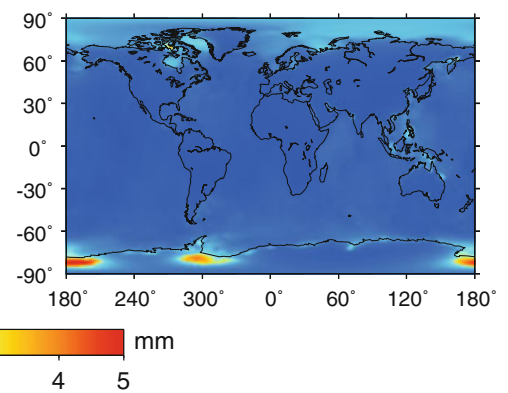

Fig. 9 RMS of M2 ocean tide loading height displacement vector differences $(0.25$ degree grid) computed using five recent ocean tide models (CSR4.0, FES2004, GOT00.2, NAO.99b, TPXO6.2) and the SPOTL software. The RMSs have been capped at $5 \mathrm{~mm}$ for clarity, which is mainly only exceeded in the Weddell Sea. Modified from Penna et al.(2008)

\subsection{Local Site Effects}

Local site effects include actual local site motions, such as monument/antenna thermal expansion, or apparent motion, such as due to local unmodeled GPS carrier phase multipath. Local site effects impact geodetic velocities in two different ways. First, at co-located reference sites, monument motion affects the local site tie information used in the TRF computation. Combinations of TRFs stemming from multi-technique space geodetic observations suffer from specific intra-technique biases, which can affect and reduce the overall accuracy of the final frame estimation. In particular combinations of TRFs can benefit the estimation of specific geodetic parameters supplied by various techniques, while the reference frame realisation may be improved by compensating the shortcomings related to single technique solutions. Combined solutions performed on common parameters highlight the discrepancies between the local tie and the space geodetic observations (e.g., Ray and Altamimi 2005; Altamimi et al. 2007; Krügel et al. 2007; Thaller et al. 2007). These discrepancies have a range of origins and the stability of the reference points of co-located instruments is an important factor. For example, the reference points of large VLBI telescopes have instabilities due to thermal expansion and gravity. The state of-theart in VLBI thermal deformation and how they are routinely treated in data analysis is described in Nothnagel (2009), while an example of quantitative evaluation of signal path variation induced by gravity in large VLBI telescopes is described in Sarti et al. (2009). Finally, the production of the ITRF is sensitive to the orientation of the local ties in the global frame (Abbondanza et al. 2009), and also to the stability and measurement frequency of the local tie. 
The second way in which local site effects impact velocities is by directly adding noise and/or bias to estimated site velocities. For example, using coordinate time series for longrunning short $(<100 \mathrm{~m})$ GPS baselines King and Williams (2009) showed that four of the ten baselines tested exhibited secular rates with velocities $>0.25 \mathrm{~mm} /$ year lasting several years. Most baselines showed substantial annual signal in one or more coordinate components. The origins of many of the observed motions are unknown. Signals with periods close to those of K1 and K2 were identified on all baselines and S1 at some. Monument thermal expansion substantially contributed to signal at mainly annual periods in some cases, and multipath likely also contributed substantial noise. Importantly, Langbein (2008) reported that local geology may be the dominant influence on noise characteristics of geodetic monuments. Hill et al. (2009) using a short-baseline network (baselines between 0.01 and $1 \mathrm{~km}$ ) of some of the best-quality monuments in a dry environment, found seasonal cycles in the time series of the horizontal and vertical components of all baselines, with amplitudes reaching $0.6 \mathrm{~mm}$. Cycles lagged seasonal cycles in local temperature measurements by about one month for sites with identical monuments, suggesting a relation to thermal expansion of the bedrock, but no lag for mixed monuments, implying thermal expansion of the upper ground layers and the monuments themselves. They showed that multipath was unlikely to contribute significantly to the seasonal cycles in the horizontal time series. They also found surprisingly large secular rates, up to $0.3 \mathrm{~mm} / \mathrm{year}$, compared with previous estimates of tectonic activity for the area. In a further study, King and Watson (2010) examined the effects of radiating near field multipath. They showed that time-constant multipath combined with the GPS satellite constellation, which has evolved over time, is sufficient to produce substantial signal across the entire frequency spectrum, including apparent offsets, velocity biases of several tenths of a millimetre per year and time-correlated noise. Simulation results for three typical sites are shown in Fig. 10 for the case of a synthetic perfectly repeated and unchanged constellation (left panels) and the GPS constellation defined by the broadcast orbits (right panels). Time series were often degraded further when real tracking geometries were introduced into the simulations. Noise characteristics of the resulting time series showed spectral indices higher than flicker noise but lower than random walk. Simple attempts to mitigate the effect through modification of the stochastic model were partly successful. In addition, the effects of unmodelled signal from the reactive near field were studied by Dilssner et al. (2008) who also found substantial time-variable noise in GPS coordinate time series. A robust method to model (e.g., Park et al. 2004) or mitigate multipath and scattering effects (e.g., Elosegui et al. 1995) must be a high priority in the GPS community and similar studies are required for DORIS.

Of the various potential local site effects, motion due to thermal expansion is, at present, one of the strongest candidates for reliable modelling. However, there is not a detailed model for correcting for thermal expansion of GPS, DORIS or SLR monuments. Furthermore, for VLBI antennas more refined models are required that represent the asymmetrical effects of thermal and gravitational deformations. Below we emphasise some key points that particularly concern GPS (and DORIS) monuments and ground control network pillars at sites with co-located instruments. For a complete description of the DORIS monumentation, the network renovation, and the description of the current co-locations with other geodetic techniques, see Fagard (2006) and Willis et al. (2009).

If a monument is comprised of simple reinforced concrete or steel pillars, and is sufficiently tall, the difference in structure temperature with respect to a reference temperature could induce significant vertical and, in some circumstances, horizontal instabilities in a pillar's top (Lidberg and Lilje 2007). 


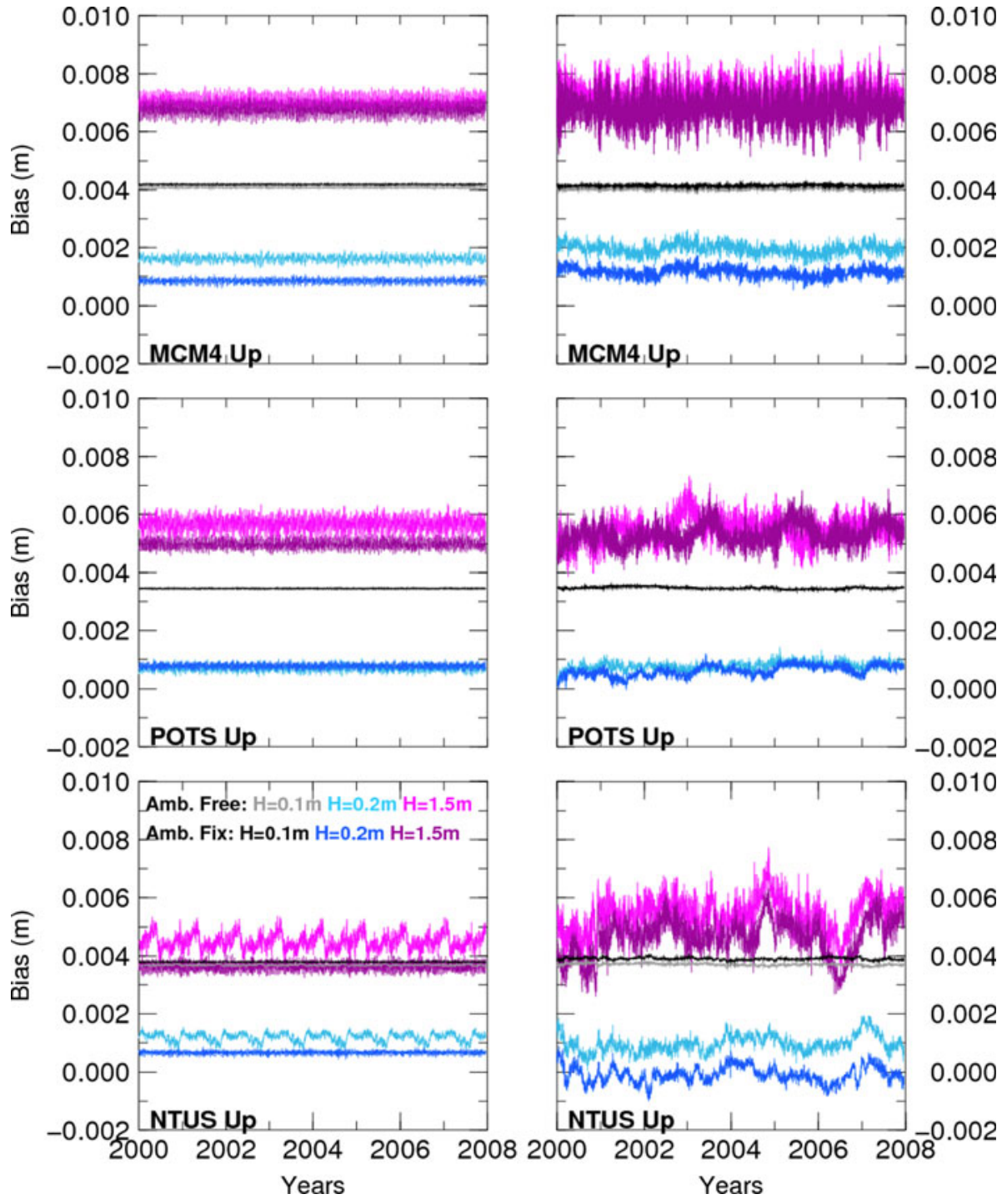

Fig. 10 Simulated height bias time series for three sites when propagating time-constant multipath with three different heights above the horizontal multipath reflector for a constant constellation (left) and an evolving constellation (right). Ambiguity free (lighter shades) and ambiguity fixed (darker shades) solutions are shown. Reproduced from King and Watson (2010)

For more refined composed-shell monuments, reticular or complex structures, 3-d finite element method (FEM) software packages can be used to evaluate the heat transfer and deformations at each nodal point of the structure. However, the accuracy of the output from the FEM is only as good as the input is representative of the observed phenomenon; therefore, validation measurements are advised. Further efforts to understand and model existing monuments are clearly required, leading to improved monument design for future installations. Bedrock thermal expansion may also be an important noise source (Dong 
et al. 2002). For example, Yan et al. (2009) showed that seasonal bedrock thermal expansion may reach $\sim 1.3 \mathrm{~mm}$ in some regions, most notably at high latitudes. Geodetic observatory stakeholders must be aware of the implications connected to obtaining an accurate correction for local site effects and are encouraged to install independent continuously operating measurement systems, such as tiltmeters, temperature sensors on the structures, invar wires systems, etc., and then conduct experimental tests with the aim of quantifying these effects.

\section{Velocity Estimation and Reference Frame Realisation}

Having reviewed the observation-level models and their effects on relative site velocities, we now consider the accuracy of the reference frame to which they refer. The stacking of GPS site position solutions to estimate velocities is a crucial step in obtaining accurate velocities from which to interpret GIA. Even a relatively small oversight in data editing at this stage can lead to inaccurate results. Likewise, the importance of the reference frame realisation should not be underestimated; an error in the frame origin directed along the $\mathrm{Z}$ axis has almost $100 \%$ effect on vertical velocities observed near centres of GIA. The highly precise regional GPS reference frames often constructed for tectonic studies (e.g., Wdowinski et al. 1997) are generally not suitable for studying GIA. Such frames have been successfully used (Dietrich et al. 2005) to study GIA but in most aspects GIA studies demand a reference frame with a globally accessible origin such as the Earth's centre of mass. Realising an accurate global reference frame places the greatest demand on both the geodetic techniques and our knowledge of global scale processes. In this respect the observation level corrections discussed in Sect. 3 and the velocity estimation discussed in Sect. 4.1 culminate via frame realisation as a limit on global GPS vertical accuracy. Regardless of GPS solution accuracy, therefore, commensurate advances in the reference frame realisation are also essential.

\subsection{Velocity Estimation}

Broadly speaking the major features that contaminate GPS velocity estimation (in order of importance) are linear (step-like) offsets, co-seismic and post-seismic crustal deformation, periodic signals and temporally correlated noise. Fortunately the major GIA centres are not heavily impacted by seismic activity; however, an indirect effect remains through the reference frame which still relies on some affected sites. Systematic effects remnant from insufficient or altered observation level modelling can appear as offsets, periodic signals or temporally correlated noise.

GPS time series are often contaminated by offsets, the majority of which are likely to be artificial in nature as opposed to true crustal motion. These artificial offsets can be due to environmental, equipment malfunction, equipment change and even human error. The effect, whether the offset is known or unknown, is always to increase the uncertainty of the estimated velocity (Williams 2003). The switch from combining velocities to produce ITRF2000 to combining site time series to produce ITRF2005 (Altamimi et al. 2007) resulted in a more reliable frame because of the ability to consistently treat linear site offsets. Untreated offsets will always cause the most problems, yet the worst case for undetected offsets is that they can mimic random-walk noise which could be attributed to monument noise. 
Seasonal signals are to be expected in GPS site time series, in the least due to atmospheric and hydrological loading (see Sect. 3.6). Seasonal signals can significantly bias site velocities, particularly if the time series are shorter than 2.5 years (Blewitt and Lavallee 2002). In addition to seasonal signals, periodic signals at 13.66 and 14.22 days have also been detected in simulated and real GPS time series (Penna and Stewart 2003; Williams et al. 2004) and significant signals with periods equal to the GPS year and its harmonics (Amiri-Simkooei et al. 2007; Ray et al. 2008). In the presence of white noise, estimating seasonal signals should alleviate their effect on velocities (Blewitt and Lavallee 2002); however, given the presence of offsets and time correlated noise it is difficult to come up with hard and fast rules for their treatment. Characterisation of GPS seasonal signals using hydrological loading models (van Dam et al. 2001; Dong et al. 2002) or GRACE measurements (Davis et al. 2004; King et al. 2006; van Dam et al. 2007) has shown mixed results, although with some recent improvement using state-of-the-art GPS reprocessing (Tregoning et al. 2009). In theory with long time series, seasonal loading signals are less of an issue. As mentioned previously, a more important signal, particularly in Greenland and some regions of Antarctica, is due to elastic rebound resulting from contemporaneous local ice loading/unloading e.g., Khan et al. (2007).

\subsection{Noise Characteristics of Site Coordinate Time Series}

It is now widely established that GPS coordinate time series contain some form of temporally correlated noise along with the expected white noise. The primary effect of this noise is to increase the uncertainties of any parameters estimated from the data, for example site velocities. The original form of this noise was expected to be random walk due to monument instability, based on observations of continuous strain meter data (Wyatt 1982; Wyatt 1989; Wyatt et al. 1989) and two-colour electronic distance meter data (Langbein and Johnson 1995). However the first major studies on the noise content of continuous GPS data found that a more appropriate model of the noise was flicker plus white noise (Zhang et al. 1997; Mao et al. 1999). Since then the number of GPS sites, the length of the time series and the number of potential stochastic models have all increased. Langbein (2004) introduced several other classes of noise that could be used; first-order Gauss Markov, generalised Gauss Markov, and band-pass noise. Amiri-Simkooei et al. (2007) confirmed the presence of flicker noise and white noise but also a short memory signal modelled as a first-order autoregressive noise process.

The general consensus is that flicker plus white noise (or even a flicker plus random walk plus white noise) is still a reasonable model to use. Langbein (2008) suggested that such a model is attractive because it can provide general users with guidelines to the levels of noise to apply to the data. Williams et al. (2004) found that both the coloured noise and the white noise showed latitude dependence (higher nearer the equator) and a hemispherical bias (larger in the southern hemisphere). They also noted that the noise has been decreasing in amplitude since the first networks began most probably due to improvements in GPS processing and observation-level models. Table 3 provides a set of noise amplitudes for global and regional (common noise removed) time series for southern hemisphere (lower than $30^{\circ}$ South), equatorial and northern hemisphere (higher than $30^{\circ}$ North) sites. An estimate of the expected site velocity uncertainty after 5, 10, and 20 years is given in Table 4. Short baseline studies, attractive for monument stability studies since common mode errors are differenced to negligible levels, still provide no convincing evidence for random walk noise being dominant (King and Williams 2009). They proposed an upper limit of $0.5 \mathrm{~mm} / \sqrt{ }$ year for IGS sites based on an analysis of 10 long-running short 
Table 3 Typical flicker noise and white noise amplitudes for the north, east and vertical components for precise point positioning (PPP), double difference (DD), and either PPP or DD with the common mode error removed using stacking

\begin{tabular}{|c|c|c|c|c|c|c|c|}
\hline \multirow[t]{2}{*}{ Solution } & \multirow[t]{2}{*}{ Area } & \multicolumn{3}{|c|}{ Flicker noise $\left(\mathrm{mm} /\right.$ year $\left.^{1 / 4}\right)$} & \multicolumn{3}{|c|}{ White noise $(\mathrm{mm})$} \\
\hline & & North & East & Up & North & East & Up \\
\hline \multirow[t]{3}{*}{ DD } & Southern Hemisphere & 8.0 & 9.3 & 21.6 & 2.2 & 3.4 & 5.8 \\
\hline & Equatorial & 8.5 & 14.9 & 30.5 & 2.6 & 5.0 & 8.2 \\
\hline & Northern Hemisphere & 4.7 & 5.9 & 19.3 & 1.2 & 1.7 & 3.5 \\
\hline \multirow[t]{3}{*}{ PPP } & Southern Hemisphere & 10.3 & 11.3 & 25.2 & 3.6 & 5.3 & 8.7 \\
\hline & Equatorial & 7.0 & 15.8 & 27.6 & 3.6 & 7.3 & 12.5 \\
\hline & Northern Hemisphere & 8.1 & 8.7 & 21.6 & 2.7 & 3.7 & 6.5 \\
\hline Stacked & Regional & 2.2 & 2.2 & 7.3 & 0.8 & 0.9 & 3.2 \\
\hline
\end{tabular}

The statistics are based on the Williams et al. (2004) data and are calculated from the fit to the JPL and SOPAC solutions (using equation 5 of Williams et al. (2004) with sites as shown in their Fig. 6). The amplitudes are also divided into latitudinal bands; southern hemisphere (south of $-30^{\circ}$ ), Equatorial, and northern hemisphere (north of $30^{\circ}$ ). For the PPP and DD computations, respectively, 268 and 207 sites were used with average spans of 2.5 year and 3.6 year and maximum spans 9.8 year and 10.7 year

Table 4 Theoretical site velocity uncertainties after 5, 10 and 20 years for the north, east and vertical components for PPP, double difference (DD), and either PPP or DD with the common mode error removed using stacking

\begin{tabular}{|c|c|c|c|c|c|c|c|c|c|c|}
\hline \multirow[t]{2}{*}{ Solution } & \multirow[t]{2}{*}{ Area } & \multicolumn{3}{|c|}{5 Years $(\mathrm{mm} /$ year $)$} & \multicolumn{3}{|c|}{10 Years (mm/year) } & \multicolumn{3}{|c|}{20 Years (mm/year) } \\
\hline & & North & East & Up & North & East & Up & North & East & Up \\
\hline \multirow[t]{3}{*}{ DD } & Southern Hemisphere & 0.59 & 0.68 & 1.58 & 0.29 & 0.34 & 0.79 & 0.15 & 0.17 & 0.39 \\
\hline & Equatorial & 0.63 & 1.09 & 2.23 & 0.31 & 0.55 & 1.11 & 0.16 & 0.27 & 0.56 \\
\hline & Northern Hemisphere & 0.35 & 0.43 & 1.41 & 0.17 & 0.22 & 0.71 & 0.09 & 0.11 & 0.35 \\
\hline \multirow[t]{3}{*}{ PPP } & Southern Hemisphere & 0.75 & 0.83 & 1.85 & 0.38 & 0.42 & 0.92 & 0.19 & 0.21 & 0.46 \\
\hline & Equatorial & 0.52 & 1.17 & 2.04 & 0.26 & 0.58 & 1.01 & 0.13 & 0.29 & 0.51 \\
\hline & Northern Hemisphere & 0.60 & 0.64 & 1.58 & 0.30 & 0.32 & 0.79 & 0.15 & 0.16 & 0.39 \\
\hline Stacked & Regional & 0.16 & 0.16 & 0.54 & 0.08 & 0.08 & 0.27 & 0.04 & 0.04 & 0.13 \\
\hline
\end{tabular}

The uncertainties are also divided into latitudinal bands; southern hemisphere (south of $-30^{\circ}$ ), Equatorial, and northern hemisphere (north of $30^{\circ}$ ). Uncertainties are based on the values given in Table 3

baselines. Hill et al. (2009) found similar values for random walk amplitude for a shortbaseline GPS network.

Despite no real evidence for random walk noise so far, three studies have tried to correlate the amount of noise in the time series to the type of monument used at the site. Williams et al. (2004) found that deep drilled braced monuments appeared to be the most stable. However, Beavan (2005) found that the concrete piers used in New Zealand offered similar levels of stability as the braced monuments in the previous study. Langbein (2008), looking at sites in Southern California and Nevada, found that location was the biggest predictor of noise levels. Sites with the lowest noise levels were located within dry deserts whereas those installed within regions of active groundwater or oil pumping had the largest noise levels. 
The same biases and inconsistencies in satellite orbits, processing strategies, residual tropospheric and ionospheric errors that introduce temporal correlations are also correlated over large regions (e.g., Wdowinski et al. 1997; Williams et al. 2004). Regional spatial filtering of GPS time series was introduced by Wdowinski et al. (1997). A common mode noise was removed by stacking of the time series residuals and estimating the mean value each day. This empirical method, equivalent to a three-parameter Helmert transformation (Dong et al. 2006), was shown (see Table 3) to significantly reduce the amplitudes of the flicker and white noise in the time series (Williams et al. 2004). A more rigorous approach to the problem using principal component analysis and Karhunen-Loeve expansion was performed by Dong et al. (2006) who found that the results were similar to the stacking method because the sites were spatially correlated over large wavelengths. Other groups have also applied empirical orthogonal functions to the problem with similar results (Johansson et al. 2002). The problem of spatial and temporal correlations in the GPS time series has also divided the community into two groups. One can neglect the temporalcorrelations and include the formal between-site correlations in some form of sequential least squares to produce a correct co-variance matrix for site velocities that is essential for reference frame computations. The variances are however too optimistic because of the neglected time correlations. Conversely the spatial correlations can be neglected and the site parameters estimated from each series independent of the others. The parameter variances are then realistic but the co-variances are unresolved. If the spatial and temporal correlations are mildly orthogonal then we can treat the two things separately (Williams et al. 2004; Amiri-Simkooei 2009). The time series can be processed individually and the between-site and between-component correlations added later to form a co-variance matrix of site velocities. Conversely the spatial correlations can be accounted for in sequential least squares and the co-variances scaled to appropriate levels after.

\subsection{Plate Tectonic Deformation and Reference Frame Choice}

The dominant signal in geodetic observed displacement rates is not GIA, but plate tectonic deformation. The discussions on errors and noise thus far do not mention this since tectonic deformation is more often than not the desired signal; however, when it comes to GIA, plate tectonic deformation is a nuisance. There are two approaches: (1) remove the tectonic motion and (2) ignore it and just look at the vertical rates. Both approaches can only work in the stable, rigid areas of tectonic plates where plate motions are approximated by a rotation about a pole and vertical motion due to plate boundary activity is absent. The spatial distribution of GPS sites is now sufficient to precisely estimate (Sella et al. 2002; Kreemer and Lavallée 2006; Sella et al. 2007) and remove plate rotations and arguably there is no reason to compare only vertical rates for the major GIA regions.

Geodetic and GIA forward model derived displacement rates can only be compared within the same coordinate reference frame. Assuming rotational effects can be removed, the comparison of displacement rates (vertical or horizontal) from GIA forward models and geodetic techniques now only requires that the origin of the model reference frame and the data reference frame coincide. The conventional choice for the origin of the geodetic defined reference frame is the centre of mass of the entire Earth system (CM). This origin is generally realised by use of the ITRF (see Sect. 4.4) which has its origin dynamically defined by Satellite Laser Ranging.

To define the CM origin, GIA forward modellers use appropriate boundary conditions (Farrell 1972). Not all modellers choose such a frame (see Sect. 2.1); another choice is the centre of mass of the solid Earth (CE). The errors due to mis-matched data and model 
frames depend on the size of the longest wavelength part of the model, the degree-1 coefficients of displacement. The degree-1 components are most sensitive to a lower mantle viscosity (Greff-Lefftz 2000). Errors can be avoided by matching the frame (boundary conditions) of the model to the origin of the geodetic measurements.

The uncertainty of the realisation of an origin at CM deserves some attention. Fundamentally GPS 3-d velocities are estimated from range data that describe displacement along baselines between our chosen site and a group of reference sites (i.e. the reference frame). For the group of reference sites (with global distribution) the same range data describe the displacement along geocentric vectors connecting the site to $\mathrm{CM}$ which is dynamically defined through satellite orbits. Almost without exception, quoted GPS formal errors (even those updated to account for temporal correlations, see Sect. 4.2 above) only reflect the precision achievable along baselines between chosen sites and the reference sites; the uncertainty in the geocentric vectors (i.e. origin uncertainty) of our reference sites is not included. For GIA, where we require global rates, the uncertainty in the reference frame origin rate also needs to be included as a potential systematic (i.e., not random) bias; this error is around $2 \mathrm{~mm} /$ year. This uncertainty causes significantly different interpretations in studies of GIA and plate motion (Johansson et al. 2002; Kreemer and Lavallée 2006; Argus 2007; Argus et al. 2010). The $1.8 \mathrm{~mm} /$ year difference between ITRF2000 and ITRF2005 highlights this uncertainty and is discussed in Sect. 4.4.

Care must be taken in seeking an alternative geocentric origin. An adjustment based on regional data is not possible since shifting the origin of the frame could imply non-physical deformation (e.g. excessive strain in rigid plates) elsewhere on the globe where measurements were neglected. Argus (2007) realises an alternative to the ITRF origin by aligning geodetic results to the centre of the CE frame of the GIA model of Peltier (1994). This frame realisation is a viable alternative to ITRF; however, GIA model differences do come into effect, and are estimated to be around $1 \mathrm{~mm} /$ year. Other suitable alternative frames to ITRF for studying GIA are thin on the ground; to study GIA the frame must be geocentric so observationally the only choices are GPS, SLR and DORIS. The ITRF is arguably the best combination of these techniques however the origin at present comes solely from SLR, although we note that a GPS defined origin has been successfully used for GIA studies (Johansson et al. 2002). Technique specific frames such as the IGS realisation of ITRF have also been used (Sella et al. 2007); however, these frames have the same ITRF origin, orientation and scale definition.

\subsection{The International Terrestrial Reference Frame}

The key element of the ITRF formation is the combination of individual reference frames obtained from data processing of the four geodetic techniques (VLBI, SLR, GPS and DORIS). In principle, the strengths of particular techniques compensate the weaknesses of others, if the combination is properly constructed, a suitable weighting is applied and a sufficient number and worldwide distribution of accurate co-location sites are available. Starting with ITRF2005 (Altamimi et al. 2007), the input data for the ITRF combination are in the form of time series of site positions and Earth Orientation Parameters (EOPs). Analysis of time series of site positions is a fundamental first step in the ITRF elaboration, allowing to assess the behaviour not only of the observing sites, but also the frame parameters and in particular the physical ones, namely the origin and the scale.

Another important aspect of the ITRF construction is its datum definition in terms of its origin, scale, orientation and their time evolution. While the orientation rate is conventionally defined by imposing a no net rotation condition (Altamimi et al. 2007), the origin 
and the scale are heavily dependent on the accuracy of these parameters as provided, for the time being, by SLR and VLBI frames. Having physical properties, they are the most critical parameters of interest to Earth science applications. In the absence of techniquespecific systematic errors, and if all geophysical processes are accurately accounted for in geodetic analysis, TRF origin and scale should be stable over time, i.e. should not exhibit any drift or discontinuities over the entire time-span of the implied geodetic observations. For example, any scale or origin translation bias or drift in the ITRF definition propagates directly to the height component of the sites and their vertical velocities.

Improvements of the technique contributions to the ITRF are still expected, not only by improving their respective networks and co-location sites, but also in terms of data processing and the mitigation of their systematic errors. The latter include the systematic errors discussed above for GPS, but also for the other techniques (e.g., SLR ranging and time biases, SLR/DORIS mismodelling of the satellite orbits or troposphere or VLBI antenna deformations).

\subsection{Uncertainties in ITRF2005 Site Velocities at High Latitudes}

The accuracy of site velocities (and in particular the vertical ones) is highly dependent on the accuracy of the origin and the scale of the reference frame. Taking the ITRF2005 results as an example, the drift found in the Z-translation component of $1.8 \mathrm{~mm} /$ year with respect to the ITRF2000 induces site velocity changes in the north and vertical directions. For a site at latitude $\phi$, the velocity change is $1.8 \times \sin (\phi) \mathrm{mm} /$ year in the vertical and $1.8 \times \cos (\phi) \mathrm{mm} / \mathrm{year}$ in the north direction. Figure 11 shows the ITRF2005 sites at high latitudes (beyond 60.0 and -60.0 degrees. There are 33 GPS sites, five VLBI, 10 DORIS and only one SLR site (Metsahovi, Finland). At those sites, the Z-translation drift between ITRF2000 and ITRF2005 has minor impact on their north velocity, whereas their vertical velocity change exceeds $1 \mathrm{~mm} /$ year as illustrated by Fig. 11, restricted to sites having an ITRF2005 formal uncertainty of $1 \mathrm{~mm} /$ year.

A very significant concern in regard to the ITRF origin is the small size of the SLR network and its limited distribution. Week by week during 1995-2008 the SLR network has a maximum of 25 usable sites, with only five in the southern hemisphere; furthermore $23 \%$ of the time there are two or less sites in the southern hemisphere. This makes the ITRF origin, which is currently solely dependent on SLR, highly dependent on the

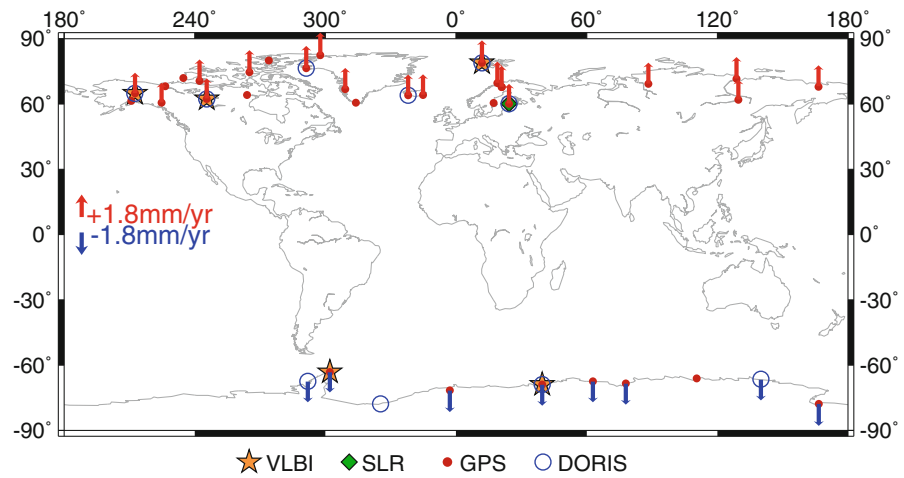

Fig. 11 ITRF2005 high latitude sites. Vertical velocity changes due to the Z-translation drift between ITRF2005 and ITRF2000 are shown for sites having a formal error less than $1 \mathrm{~mm} /$ year 
velocities of individual SLR sites. This situation will not be solved by modelling advances and can only be approached via expansion of the SLR network or involvement of GPS or DORIS in the definition of the ITRF origin.

\section{Conclusions}

Geometric geodesy offers the potential to provide new constraints on models of GIA in Antarctica and Greenland. In turn, improved GIA models will open the way for improved estimates of present-day ice mass changes and further insights into Earth structure and ice history. Until very recently the ground-based geodetic networks did not have sufficient spatial extent, particularly into the Greenland and Antarctic ice sheet interiors, to allow anything other than coarse constraints on the GIA models. Furthermore, GPS analyses were limited in terms of velocity precision and accuracy. In part, some of these limitations have now been addressed, although we have explained key areas of need, which taken pessimistically would suggest a present-day GPS vertical velocity accuracy limit of the order of a few mm/year at high latitudes, dominated by reference frame uncertainty, against a need from the GIA modelling community for velocities with accuracy closer to the $0.1 \mathrm{~mm} /$ year level. In reality, this is indeed likely to be a pessimistic assessment of accuracy as illustrated by intra- and inter-regional global sea level change estimates determined using near state-of-the-art GPS analysis (Wöppelmann et al. 2009), and the true vertical velocity accuracy measure is likely to be below $1 \mathrm{~mm} /$ year globally, with some regional and site-specific variations. The accuracy of horizontal velocities is likely to be greater than this, especially at high latitudes where the geocentre rate uncertainty may dominate the height error (see also Argus (2007)). The main challenges in terms of precision are to further reduce time-correlated noise, thereby shortening the data span required to reach a given precision.

Two clear challenges remain: (1) the need for further sites in regions of GIA, and (2) the need for improved accuracy and precision of time series. Dozens of new continuous GPS receivers have been deployed in recent years and more will be added in the near future and further deployments may be required. The difficulty and expense of installing and maintaining these sites should not, however, be underestimated and long-term funding is required.

The measurement precision of GPS receivers is 1-2 orders of magnitude smaller than the currently obtained coordinate time series precision. Therefore, there is tremendous potential to improve coordinate time series precision. The key to greater exploitation of these precise measurements is improvements to observation level models and the terrestrial reference frame. Two areas where new models are required are in orbit dynamics and site multipath, both of which may propagate into velocity bias and noise and are presently insufficiently included in geodetic-quality analysis software. Spatially dense networks with an accuracy and precision of $0.1 \mathrm{~mm} /$ year would allow new insights into the Earth system, including those that would lead to improved GIA models. That we are not yet able to attain this level should in no way prevent data collection occurring since it may be some years, at the very least 2.5 years (Blewitt and Lavallee 2002), before rigorous geodetic estimates of 3 -d site velocities may be obtained from these data. The recent rapid progress in observation level models in geodetic GPS (and also VLBI, DORIS and SLR) needs to continue for some time into the future.

Despite this progress there remain, however, confounding elements to the ground-based observation of GIA. The first of these is that very little of the two major ice sheets contain 
exposed bedrock. Indeed, less than 5\% of the area of Antarctica is ice free and not all of this is suitable for locating GPS monuments, and the interior of Greenland is entirely ice covered. Imaginative approaches of measuring GIA in ice covered regions and offshore are required. The second of these is that GPS measurements are subject to the elastic rebound of contemporaneous ice loading (Khan et al. 2007). Making co-located and contemporaneous absolute gravity (AG) measurements allows the two to be separated (Wahr et al. 1995), but AG observations co-located with GPS in Greenland and Antarctica are, at present, extremely unusual and widespread application of this technique will not be possible for some years.

Ultimately, however, integration of geodetic data sets with non-geodetic sources will provide the optimal set of constraints on models of GIA. Collaboration between geodetic specialists, GIA modellers, ice modellers, glacial geologists and sea level experts amongst others, such as in COST Action ES0701, is essential for substantial progress.

Acknowledgments This work was partially funded by COST Action ES0701. This is IPGP contribution 2629. We thank Volker Klemann and Wouter van der Wal for providing the model data used to produce Figs. 1 and 2. Matt King was part funded by a RCUK Academic Fellowship.

Open Access This article is distributed under the terms of the Creative Commons Attribution Noncommercial License which permits any noncommercial use, distribution, and reproduction in any medium, provided the original author(s) and source are credited.

\section{References}

Abbondanza C, Altamimi Z, Sarti P, Negusini M, Vittuari L (2009) Local effects of redundant terrestrial and GPS-based tie vectors in ITRF-like combinations. J Geod. doi: 10.1007/s00190-009-0321-6

Agnew DC (1996) SPOTL: some programs for ocean-tide loading. Scripps Institution of Oceanography, La Jolla

Agnew DC (1997) NLOADF: a program for computing ocean-tide loading. J Geophys Res 102(B3):51095110

Altamimi Z, Collilieux X, Legrand J, Garayt B, Boucher C (2007) ITRF2005: a new release of the international terrestrial reference frame based on time series of station positions and earth orientation parameters. J Geophys Res Solid Earth 112:B09401. doi:10.1029/2007JB004949

Amalvict M, Willis P, Wöppelmann G, Ivins ER, Bouin M-N, Testut L, Hinderer J (2009) Isostatic stability of the East Antarctic station Dumont d'Urville from long-term geodetic observations and geophysical models. Polar Res 28(2):193-202. doi:10.1111/j.1751-8369.2008.00091.x

Amiri-Simkooei AR (2009) Noise in multivariate GPS position time-series. J Geod 83(2):175-187

Amiri-Simkooei AR, Tiberius CCJM, Teunissen PJG (2007) Assessment of noise in GPS coordinate time series: methodology and results. J Geophys Res 112:B07413. doi:10.1029/2006JB004913

Argus DF (1996) Postglacial rebound from VLBI geodesy: on establishing vertical reference. Geophys Res Lett 23(9):973-976

Argus DF (2007) Defining the translational velocity of the reference frame of Earth. Geophys J Int 169(3): $830-838$

Argus DF, Peltier WR (2010) Constraining models of postglacial rebound using space geodesy: a detailed assessment of model ICE-5G (VM2) and its relatives. Geophys J Int 181(2):697-723. doi:10.1111/ j.1365-246X.2010.04562.x

Argus DF, Gordon RG, Heflin MB, Ma C, Eanes RJ, Willis P, Peltier WR, Owen SE (2010) The angular velocities of the plates and the velocity of Earth's centre from space geodesy. Geophys J Int 180(3): 913-960. doi:10.1111/j.1365-246X.2009.04463.x

Barletta VR, Sabadini R, Bordoni A (2008) Isolating the PGR signal in the GRACE data: impact on mass balance estimates in Antarctica and Greenland. Geophys J Int 172(1):18-30

Baueršima I (1983) NAVSTAR/Global Positioning System (GPS) II. Mitteilungen der Satelliten-Beobachtungsstation Zimmerwald, Astronomical Institute. University of Bern, Bern 
Beavan J (2005) Noise properties of continuous GPS data from concrete pillar geodetic monuments in New Zealand and comparison with data from U.S. deep drilled braced monuments. J Geophys Res Solid Earth 110:B08410. doi:10.1029/2005JB003642

Beutler G, Brockmann E, Gurtner W, Hugentobler U, Mervart L, Rothacher M (1994) Extended orbit modeling techniques at the CODE processing center of the international GPS service for geodynamics (IGS): theory and initial results. Manuscr Geod 19:367-386

Bevis M, Kendrick E, Smalley R Jr, Dalziel I, Caccamise D, Sasgen I, Helsen M, Taylor FW, Zhou H, Brown A, Raleigh D, Willis M, Wilson T, Konfal S (2009) Geodetic measurements of vertical crustal velocity in West Antarctica and the implications for ice mass balance. Geochem Geophys Geosyst 10:Q10005. doi:10.1029/2009GC002642

Blewitt G (2003) Self-consistency in reference frames, geocenter definition, and surface loading of the solid Earth. J Geophys Res Solid Earth 108(B2):2103. doi:10.1029/2002JB002082

Blewitt G, Lavallee D (2002) Effect of annual signals on geodetic velocity. J Geophys Res Solid Earth 107(B7):2145. doi:10.1029/2001JB000570

Bock D, Noomen R, Scherneck HG (2005) Atmospheric pressure loading displacement of SLR stations. J Geodyn 39(3):247-266

Boehm J, Niell A, Tregoning P, Schuh H (2006a) The Global Mapping Function (GMF): a new empirical mapping function based on numerical weather model data. Geophys Res Lett 33:L07304. doi: 10.1029/2005GL025546

Boehm J, Werl B, Schuh H (2006b) Troposphere mapping functions for GPS and very long baseline interferometry from European Centre for Medium-Range Weather Forecasts operational analysis data. J Geophys Res 111:B02406. doi:10.1029/2005JB003629

Boehm J, Heinkelmann R, Schuh H (2007) Short note: a global model of pressure and temperature for geodetic applications. J Geod 81(10):679-683

Bos MS, Baker TF (2005) An estimate of the errors in gravity ocean tide loading computations. J Geod 79(1-3):50-63

Buffett BA, Mathews PM, Herring TA, Shapiro II (1993) Forced nutations of the earth: contributions prom the effects of ellipticity and rotation on the elastic deformations. J Geophys Res 98(B12):21659-21676

Cardellach E, Elosegui P, Davis JL (2007) Global distortion of GPS networks associated with satellite antenna model errors. J Geophys Res Solid Earth 112:B07405. doi:10.1029/2006JB004675

Chao BF, Dehant V, Gross RS, Ray RD, Salstein DA, Watkins MM, Wilson CR (2000) Space geodesy monitors mass transports in global geophysical fluids. Eos Trans Am Geophys Union 81(22): 247, 249250

Chen JL, Wilson CR, Blankenship DD, Tapley BD (2006a) Antarctic mass rates from GRACE. Geophys Res Lett 33:L11502. doi:10.1029/2006GL026369

Chen JL, Wilson CR, Tapley BD (2006b) Satellite gravity measurements confirm accelerated melting of Greenland ice sheet. Science 313(5795):1958-1960

Dach R, Springer T, Altamimi Z (2008) Experiment on impact of constrained orbit parameters on station coordinates. In: International GNSS Service Analysis Center workshop 2008, Miami Beach, FL, USA

Dach R, Brockmann E, Schaer S, Beutler G, Meindl M, Prange L, Bock H, Jäggi A, Ostini L (2009) GNSS processing at CODE: status report. J Geod 83(3-4):353-366 (Special issue: The International GNSS Service (IGS) in a changing landscape of global navigation satellite systems, guest editor C. Rizos)

Davis JL, Herring TA, Shapiro II, Rogers AEE, Elgered G (1985) Geodesy by radio interferometry: effects of atmospheric modeling errors on estimates of baseline length. Radio Sci 20(6):1593-1607

Davis JL, Elgered G, Niell AE, Kuehn CE (1993) Ground-based measurement of gradients in the "wet" radio refractivity of air. Radio Sci 28(6):1003-1018

Davis JL, Elosequi P, Mitrovica JX, Tamisiea ME (2004) Climate-driven deformation of the solid Earth from GRACE and GPS. Geophys Res Lett 31(24):L24605. doi:10.1029/2004GL021435

Dietrich R, Rülke A (2008) A precise reference frame for Antarctica from SCAR GPS campaign data and some geophysical implications. In: Capra A, Dietrich R (eds) Geodetic and geophysical observations in Antarctica. Springer, Berlin, pp 1-10

Dietrich R, Dach R, Engelhardt G, Ihde J, Korth W, Kutterer H, Lindner K, Mayer M, Menge F, Miller H, Muller C, Niemeier W, Perlt J, Pohl M, Salbach H, Schenke HW, Schone T, Seeber G, Veit A, Volksen C (2001) ITRF coordinates and plate velocities from repeated GPS campaigns in Antarctica-an analysis based on different individual solutions. J Geod 74:756-766

Dietrich R, Rulke A, Ihde J, Lindner K, Miller H, Niemeier W, Schenke HW, Seeber G (2004) Plate kinematics and deformation status of the Antarctic Peninsula based on GPS. Glob Planet Change 42(14):313-321

Dietrich R, Rulke A, Scheinert M (2005) Present-day vertical crustal deformations in West Greenland from repeated GPS observations. Geophys J Int 163(3):865-874 
Dilssner F, Seeber G, Wubbena G, Schmitz M (2008) Impact of near-field effects on the GNSS position solution. In: Proceedings of ION GNSS 2008, Savannah, GA. September 16-19, pp 612-623

Dong D, Fang P, Bock Y, Cheng MK, Miyazaki S (2002) Anatomy of apparent seasonal variations from GPS-derived site position time series. J Geophys Res 107(B4): art. no.-2075

Dong D, Fang P, Bock Y, Webb F, Prawirodirdjo L, Kedar S, Jamason P (2006) Spatiotemporal filtering using principal component analysis and Karhunen-Loeve expansion approaches for regional GPS network analysis. J Geophys Res 111:B03405. doi:10.1029/2005JB003806

Donnellan A, Luyendyk BP (2004) GPS evidence for a coherent Antarctic plate and for postglacial rebound in Marie Byrd Land. Glob Planet Change 42(1-4):305-311

Dow JM, Neilan RE, Rizos C (2009) The International GNSS Service in a changing landscape of global navigation satellite systems. J Geod 83:191-198. doi:10.1007/s00190-008-0300-3

Dziewonski AM, Anderson DL (1981) Preliminary reference earth model. Phys Earth Planet Interiors 25(4):297-356

Eanes RJ, Bettadpur S (1996) The CSR3.0 global ocean tide model: diurnal and semi-diurnal ocean tides from TOPEX/POSEIDON altimetry. The University of Texas Center for Space Research

Egbert GD, Erofeeva SY (2002) Efficient inverse modeling of barotropic ocean tides. J Atmos Ocean Technol 19(2):183-204. doi:10.1175/1520-0426(2002)019 $\leq 0183: E I M O B O \geq 2.0 . C O ; 2$

Ekstrom G, Dziewonski A (1998) The unique anisotropy of the Pacific upper mantle. Nature 394:168-172

Elosegui P, Davis JL, Jaldehag RTK, Johansson JM, Niell AE, Shapiro II (1995) Geodesy using the global positioning system - the effects of signal scattering on estimates of site position. J Geophys Res 100(B6):9921-9934

Fagard H (2006) Twenty years of evolution for the DORIS permanent network: from its initial deployment to its renovation. J Geod 80(8-11):429-456

Farrell WE (1972) Deformation of the earth by surface loads. Rev Geophys Space Phys 10(3):761-797

Farrell WE, Clark JA (1976) Postglacial sea-level. Geophys J R Astronom Soc 46(3):647-667

Flohrer C (2008) Mutual validation of satellite-geodetic techniques and its impact on GNSS orbit modeling. $\mathrm{PhD}$ thesis, University of Bern

Fritsche M, Dietrich R, Knofel C, Rulke A, Vey S, Rothacher M, Steigenberger P (2005) Impact of higherorder ionospheric terms on GPS estimates. Geophys Res Lett 32(23):L23311. doi:10.1029/2005 GL024342

Fukuzaki Y, Shibuya K, Doi K, Ozawa T, Nothnagel A, Jike T, Iwano S, Jauncey DL, Nicolson GD, McCulloch PM (2005) Results of the VLBI experiments conducted with Syowa Station, Antarctica. J Geod 79(6-7):379-388. doi:10.1007/s00190-005-0476-8

Ge M, Gendt G, Dick G, Zhang FP, Reigber C (2005) Impact of GPS satellite antenna offsets on scale changes in global network solutions. Geophys Res Lett 32(6): art. no.-L06310

Gobinddass ML, Willis P, de Viron O, Sibthorpe A, Zelensky NP, Ries JC, Ferland R, Bar-Sever Y, Diament M, Lemoine FG (2009) Improving DORIS geocenter time series using an empirical rescaling of solar radiation pressure models. Adv Space Res 44(11):1279-1287

Görres B, Campbell J, Becker M, Siemes M (2006) Absolute calibration of GPS antennas: laboratory results and comparison with field and robot techniques. GPS Solut 10(2):136-145

Greff-Lefftz M (2000) Secular variation of the geocenter. J Geophys Res 105(B11):25685-25692

Griffiths J, Ray J (2008) On the precision and accuracy of IGS orbits. J Geod 83(3):277-287

Heil P (2006) Atmospheric conditions and fast ice at Davis, East Antarctica:a case study. J Geophys Res Oceans 111:C05009. doi:10.1029/2005JC002904

Hernández-Pajares M, Juan JM, Sanz J, Oru R (2007) Second-order ionospheric term in GPS: implementation and impact on geodetic estimates. J Geophys Res 112:B08417. doi:10.1029/2006JB004707

Hill EM, Davis JL, Elosegui P, Wernicke B, Niemi NA (2009) Characterization of site-specific GPS errors using a short-baseline network of braced monuments at Yucca Mountain, southern Nevada. J Geophys Res 114:B11402. doi:10.1029/2008JB006027

Ivins ER, James TS (2005) Antarctic glacial isostatic adjustment: a new assessment. Antarct Sci 17(4):541553. doi:10.1017/S0954102005002968

Jiang Y, Dixon TH, Wdowinski S (2010) Accelerating uplift in the North Atlantic region as an indicator of ice loss. Nat Geosci. doi:10.1038/ngeo845

Johansson JM, Davis JL, Scherneck HG, Milne GA, Vermeer M, Mitrovica JX, Bennett RA, Jonsson B, Elgered G, Elosegui P, Koivula H, Poutanen M, Ronnang BO, Shapiro II (2002) Continuous GPS measurements of postglacial adjustment in Fennoscandia-1. Geodetic results. J Geophys Res Solid Earth 107(B8):28

Kedar S, Hajj GA, Wilson BD, Heflin MB (2003) The effect of the second order GPS ionospheric correction on receiver positions. Geophys Res Lett 30(16):1829. doi:10.1029/2003GL017639 
Khan SA, Wahr J, Stearns LA, Hamilton GS, van Dam T, Larson KM, Francis O (2007) Elastic uplift in southeast Greenland due to rapid ice mass loss. Geophys Res Lett 34:L21701. doi:10.1029/2007 GL031468

Khan SA, Wahr J, Leuliette E, van Dam T, Larson KM, Francis O (2008) Geodetic measurements of postglacial adjustments in Greenland. J Geophys Res 113:B02402. doi:10.1029/2007JB004956

Khan SA, Wahr J, Bevis M, Velicogna I, Kendrick E (2010) Spread of ice mass loss into northwest Greenland observed by GRACE and GPS. Geophys Res Lett 37(6):L06501. doi:10.1029/2010 GL042460

King MA, Watson CS (2010) Long GPS coordinate time series: multipath and geometry effects. J Geophys Res 115:B04403. doi:10.1029/2009JB006543

King MA, Williams SD (2009) Apparent stability of GPS monumentation from short-baseline time series. J Geophys Res 114:B10403. doi:10.1029/2009JB006319

King MA, Moore P, Clarke PJ, Lavallée DA (2006) Choice of optimal averaging radii for temporal GRACE gravity solutions, a comparison with GPS and satellite altimetry. Geophys J Int 166(1):1-11. doi: 10.1111/j.1365-246X.2006.03017.x

King MA, Watson CS, Penna NT, Clarke PJ (2008) Subdaily signals in GPS observations and their effect at semiannual and annual periods. Geophys Res Lett 35:L03302. doi:10.1029/2007GL032252

Klemann V, Martinec Z, Ivins ER (2008) Glacial isostasy and plate motion. J Geodyn 46(3-5):95-103

Kreemer C, Lavallée DA (2006) On the stability of a geodetic no-net-rotation frame and its implication for the International Terrestrial Reference Frame. Geophys Res Lett 33:L17306. doi:10.1029/2006 GL027058

Krügel M, Thaller D, Tesmer V, Rothacher M, Angermann D, Schmid R (2007) Tropospheric parameters: combination studies based on homogeneous VLBI and GPS data. J Geod 81(6):515-527

Langbein J (2004) Noise in two-color electronic distance meter measurements revisited. J Geophys Res Solid Earth 109:B04406. doi:10.1029/2003JB002819

Langbein J (2008) Noise in GPS displacement measurements from Southern California and Southern Nevada. J Geophys Res Solid Earth 113:B05405. doi:10.1029/2007JB005247

Langbein J, Johnson H (1995) Noise level of geodetic monuments. Eos Trans. AGU, 76(46): Fall Meet. Suppl, F142

Latychev K, Mitrovica JX, Ishii M, Chan N-H, Davis JL (2009) Body tides on a 3-D elastic earth: toward a tidal tomography. Earth Planet Sci Lett 277(1-2):86-90

Lefevre F, Lyard FH, Le Provost C, Schrama EJO (2002) FES99: a global tide finite element solution assimilating tide gauge and altimetric information. J Atmos Ocean Technol 19(9):1345-1356

Lidberg M, Lilje M (2007) Evaluation of monument stability in the SWEPOS GNSS network using terrestrial geodetic methods-up to 2003. LMV, Rapport

Luthcke SB, Zwally HJ, Abdalati W, Rowlands DD, Ray RD, Nerem RS, Lemoine FG, McCarthy JJ, Chinn DS (2006) Recent Greenland ice mass loss by drainage system from satellite gravity observations. Science 314(5803):1286-1289

MacMillan DS, Gipson JM (1994) Atmospheric-pressure loading parameters from very long baseline interferometry observations. J Geophys Res Solid Earth 99(B9):18081-18087

Mader GL (1999) GPS antenna calibration at the National Geodetic Survey. GPS Solut 3(1):50-58

Makinen J, Amalvict M, Shibuya K, Fukuda Y (2007) Absolute gravimetry in Antarctica: Status and prospects. J Geodyn 43(3):339-357. doi:10.1016/j.jog.2006.08.002

Manabe S, Sato T, Sakai S, Yokoyama K (1991) Atmospheric loading effect on VLBI observations. NOAA techical report

Mao AL, Harrison CGA, Dixon TH (1999) Noise in GPS coordinate time series. J Geophys Res 104(B2):2797-2816

Mathews PM, Buffett BA, Shapiro II (1995) Love numbers for a rotating spheroidal earth—new definitions and numerical values. Geophys Res Lett 22(5):579-582

Mathews PM, Dehant V, Gipson JM (1997) Tidal station displacements. J Geophys Res 102(B9):2046920477

Matsumoto K, Takanezawa T, Ooe M (2000) Ocean tide models developed by assimilating TOPEX/ POSEIDON altimeter data into hydrodynamical model: a global model and a regional model around Japan. J Oceanogr 56(5):567-581

McCarthy DD, Petit G (2004) IERS Conventions (2003). IERS technical note 32, Frankfurt am Main: Verlag des Bundesamts für Kartographie und Geodäsie

Menge F, Seeber G, Völksen C, Wübbena G, Schmitz M (1998) Results of absolute field calibration of GPS antenna PCV. In: Proceedings ION GPS-98, Nashville, Tennessee. September 15-18, 1998, pp 31-38

Milne GA, Davis JL, Mitrovica JX, Scherneck HG, Johansson JM, Vermeer M, Koivula H (2001) Spacegeodetic constraints on glacial isostatic adjustment in Fennoscandia. Science 291(5512):2381-2385 
Milne GA, Mitrovica JX, Scherneck H-G, Davis JL, Johansson JM, Koivula H, Vermeer M (2004) Continuous GPS measurements of postglacial adjustment in Fennoscandia: 2. Modeling results. J Geophys Res 109:B02412. doi:10.1029/2003JB002619

Mitrovica JX, Forte AM (2004) A new inference of mantle viscosity based upon joint inversion of convection and glacial isostatic adjustment data. Earth Planet Sci Lett 225(1-2):177-189

Mitrovica JX, Milne GA (2003) On post-glacial sea level: I. General theory. Geophys J Int 154(2):253-267

Munk WH, Cartwright DE (1966) Tidal spectroscopy and prediction. Philos Proc R Soc Lond 259(A1105):533-581

Nakada M, Lambeck K (1989) Late Pleistocene and Holocene sea-level change in the Australian region and mantle rheology. Geophys J 96(3):497-517

Niell AE (2006) Interaction of atmosphere modeling and VLBI analysis strategy. In: Proceedings of IVS 2006 general meeting, Concepción, Chile. January 9-13, 2006, pp 252-256

Nothnagel A (2009) Conventions on thermal expansion modelling of radio telescopes for geodetic and astrometric VLBI. J Geod 83(8):787-792. doi:10.1007/s00190-008-0284-Z

Ohzono M, Tabei T, Doi K, Shubuya K, Sagiya T (2006) Crustal movement of Antarctica and Syowa Station based on GPS measurements. Earth Planet Space 58(7):795-804

Ostini L, Beutler G, Dach R, Hugentobler U, Ploner M, Schaer S, Urschl C (2007) Near-seasonal periods in GNSS station time series. Geophys Res Abstr 9:06586

Park KD, Elosegui P, Davis JL, Jarlemark POJ, Corey BE, Niell AE, Normandeau JE, Meertens C, Andreatta VA (2004) Development of an antenna and multipath calibration system for global positioning system sites. Radio Sci 39:RS5002. doi:10.1029/2003RS002999

Peltier WR (1976) Glacial-isostatic adjustment 2. Inverse problem. Geophys J R Astronom Soc 46(3):669-705

Peltier WR (1994) Ice age paleotopography. Science 265(5169):195-201

Peltier WR (2004) Global glacial isostasy and the surface of the ice-age earth: the ICE-5G (VM2) model and GRACE. Annu Rev Earth Planet Sci 32:111-149

Penna NT, Stewart MP (2003) Aliased tidal signatures in continuous GPS height time series. Geophys Res Lett 30(23):2184. doi:10.1029/2003GL018828

Penna NT, King MA, Stewart MP (2007) GPS height time series: short-period origins of spurious longperiod signals. J Geophys Res 112:B02402. doi:10.1029/2005JB004047

Penna N, Bos M, Baker T, Scherneck HG (2008) Assessing the accuracy of predicted ocean tide loading displacement values. J Geod 82(12):893-907

Petrie EJ, King MA, Moore P, Lavallée DA (2010a) A first look at the effects of ionospheric signal bending on a globally processed GPS network. J Geod doi:10.1007/s00190-010-0386-2

Petrie EJ, King MA, Moore P, Lavallée DA (2010b) Higher-order ionospheric effects on the GPS reference frame and velocities. J Geophys Res 115:B03417. doi:10.1029/2009JB006677

Petrov L, Boy JP (2004) Study of the atmospheric pressure loading signal in very long baseline interferometry observations. J Geophys Res Solid Earth 109:B03405. doi:10.1029/2003JB002500

Rabbel W, Schuh H (1986) The influence of atmospheric loading in VLBI-experiments. J Geophys 59(3):164-170

Ramillien G, Lombard A, Cazenave A, Ivins ER, Llubes M, Remy F, Biancale R (2006) Interannual variations of the mass balance of the Antarctica and Greenland ice sheets from GRACE. Global and Planetary Change, 53(3): 198-208, doi:10.1016/j.gloplacha.2006.06.003

Ranalli G (1995) Rheology of the earth. Kluwer, Dordrecht, p 432

Ray RD (1999) A global ocean tide model from TOPEX/POSEIDON altimetry: GOT99.2. NASA Technical Memorandum 209478

Ray RD (2001) Comparisons of global analyses and station observations of the S2 barometric tide. J Atmos Solar Terres Phys 63(10):1085-1097

Ray J, Altamimi Z (2005) Evaluation of co-location ties relating the VLBI and GPS reference frames. J Geod 79(4):189-195

Ray J, Altamimi Z, Collilieux X, Van Dam T (2008) Anomalous harmonics in the spectra of GPS position estimates. GPS Solut 12(1):55-64. doi:10.1007/s10291-007-0067-7

Raymond CA, Ivins ER, Heflin MB, James TS (2004) Quasi-continuous global positioning system measurements of glacial isostatic deformation in the Northern Transantarctic Mountains. Glob Planet Change 42(1-4):295-303

Rignot E, Bamber JL, van den Broeke MR, Davis C, Li Y, van de Berg WJ, van Meijgaard E (2008) Recent Antarctic ice mass loss from radar interferometry and regional climate modelling. Nat Geosci 1(2): 106-110. doi:10.1038/ngeo102

Rulke A, Dietrich R, Fritsche M, Rothacher M, Steigenberger P (2008) Realization of the terrestrial reference system by a reprocessed global GPS network. J Geophys Res Solid Earth 113:B08403. doi: 10.1029/2007JB005231 
Saastamoinen J (1972) Atmospheric correction for the troposphere and stratosphere in radio ranging of satellites. In: Use of artificial satellites for geodesy. American Geophysical Union, Washington, DC, pp 247-251

Sarti P, Abbondanza C, Vitttuari L (2009) Gravity-dependent signal path variation in a large VLBI telescope modelled with a combination of surveying methods. J Geod 83(11):1115-1126. doi:10.1007/s00190009-0331-4

Sasgen I, Martinec Z, Fleming K (2007) Regional ice-mass changes and glacial-isostatic adjustment in Antarctica from GRACE. Earth Planet Sci Lett 264(3-4):391-401. doi:10.1016/j.eps1.2007.09.029

Scherneck H-G (1991) A parametrized solid earth tide model and ocean tide loading effects for global geodetic baseline measurements. Geophys J Int 106:677-694

Scherneck HG, Johansson JM, Koivula H, van Dam T, Davis JL (2001) Vertical crustal motion observed in the BIFROST project. In: Proceedings of 10th international symposium on recent crustal movement, Helsinki, Finland. Aug 27-31, pp 425-441

Scherneck H-G, Johansson JM, Koivula H, van Dam T, Davis JL (2003) Vertical crustal motion observed in the BIFROST project. J Geod 35(4-5):425-441

Schmid R, Rothacher M (2003) Estimation of elevation-dependent satellite antenna phase center variations of GPS satellites. J Geodesy 77(7-8):440-446. doi:10.1007/s00190-003-0339-0

Schmid R, Rothacher M, Thaller D, Steigenberger P (2005) Absolute phase center corrections of satellite and receiver antennas-impact on global GPS solutions and estimation of azimuthal phase center variations of the satellite antenna. GPS Solutions 9(4):283-293. doi:10.1007/s10291-005-0134-x

Schmid R, Steigenberger P, Gendt G, Ge M, Rothacher M (2007) Generation of a consistent absolute phasecenter correction model for GPS receiver and satellite antennas. J Geod 81(12):781-798. doi: 10.1007/s00190-007-0148-y

Sella GF, Dixon TH, Mao AL (2002) REVEL: a model for recent plate velocities from space geodesy. J Geophys Res Solid Earth 107(B4):31

Sella GF, Stein S, Dixon TH, Craymer M, James TS, Mazzotti S, Dokka RK (2007) Observation of glacial isostatic adjustment in "stable" North America with GPS. Geophys Res Lett 34:L02306. doi: 10.1029/2006GL027081

Slabinski V (2006) IGS rapid orbits: systematic error at day boundaries. In: Proceedings of IGS workshop 2006, Darmstadt, Germany, May 08-12, 2006

Springer TA, Beutler G, Rothacher M (1999) A new solar radiation pressure model for GPS satellites. GPS Solut 2(3):50-62

Steigenberger P, Romero I, Fang P (2008) Reprocessing issues, standardization, new models. In: Proceedings of IGS workshop 2006 ESA, Darmstadt

Steigenberger P, Boehm J, Tesmer V (2009a) Comparison of GMF/GPT with VMF1/ECMWF and implications for atmospheric loading. J Geod 83(10):943-951. doi:10.1007/s00190-009-0311-8

Steigenberger P, Tesmer V, Schmid R, Rothacher M, Rülke A, Fritsche M, Dietrich R (2009b) Effects of different antenna phase center models on GPS-derived reference frame. In: Drewes $H$ (ed) Geodetic reference frames, pp. 83-88. Springer, Berlin, doi:10.1007/978-3-642-00860-3_13

Stewart MP, Penna NT, Lichti DD (2005) Investigating the propagation mechanism of unmodelled systematic errors on coordinate time series estimated using least squares. J Geod 79(8):479-489. doi: 10.1007/s00190-005-0478-6

Tapley BD, Bettadpur S, Watkins M, Reigber C (2004) The gravity recovery and climate experiment: mission overview and early results. Geophys Res Lett 31(9):L09607. doi:10.1029/2004GL019920

Thaller D, Krügel M, Rothacher M, Tesmer V, Schmid R, Angermann D (2007) Combined earth orientation parameters based on homogeneous and continuous VLBI and GPS data. J Geod 81(6):529-541

Tregoning P, Watson C (2009) Atmospheric effects and spurious signals in GPS analyses. J Geophys Res 114:B09403. doi:10.1029/2009JB006344

Tregoning P, Welsh A, McQueen H, Lambeck K (2000) The search for postglacial rebound near the Lambert Glacier, Antarctica. Earth Planet Space 52(11):1037-1041

Tregoning P, Watson C, Ramillien G, McQueen H, Zhang J (2009) Detecting hydrologic deformation using GRACE and GPS. Geophys Res Lett 36:L15401. doi:10.1029/2009GL038718

Tushingham AM, Peltier WR (1991) ICE3G-a new global-model of late Pleistocene deglaciation based upon geophysical predictions of postglacial relative sea-level change. J Geophys Res Solid Earth Planet 96(B3):4497-4523

van Dam T (in press) Statistical comparison of publicly available atmospheric loading corrections. In: Proceedings of IERS workshop on combination, GeoForschungsZentrum, Potsdam, Germany, 10-11 October 2005

van Dam TM, Herring TA (1994) Detection of atmospheric pressure loading using very long baseline interferometry measurements. J Geophys Res 99(B3):4505-4517 
van Dam T, Wahr J, Milly PCD, Shmakin AB, Blewitt G, Lavallee D, Larson KM (2001) Crustal displacements due to continental water loading. Geophys Res Lett 28(4):651-654

van Dam T, Wahr J, Lavallee D (2007) A comparison of annual vertical crustal displacements from GPS and gravity recovery and climate experiment (GRACE) over Europe. J Geophys Res Solid Earth 112:B03404. doi:10.1029/2006JB004335

Velicogna I, Wahr J (2006) Measurements of time-variable gravity show mass loss in Antarctica. Science. doi: $10.1126 /$ science. 1123785

Wahr J (1995) Earth tides. In: Ahrens TJ (ed) Global earth physics. a handbook of physical constants. AGU, Washington DC, pp 40-46

Wahr J, Dazhong H, Trupin A (1995) Predictions of vertical uplift caused by changing polar ice volumes on a viscoelastic earth. Geophys Res Lett 22(8):977-980

Wahr J, van Dam T, Larson K, Francis O (2001) Geodetic measurements in Greenland and their implications. J Geophys Res Solid Earth 106(B8):16567-16581

Wang HS, Wu P, van der Wal W (2008) Using postglacial sea level, crustal velocities and gravity-rate-ofchange to constrain the influence of thermal effects on mantle lateral heterogeneities. J Geod 46(35):104-117

Watson C, Tregoning P, Coleman R (2006) The impact of solid earth tide models on GPS coordinate and tropospheric time series. Geophys Res Lett 33:L08306. doi:10.1029/2005GL025538

Wdowinski S, Bock Y, Zhang J, Fang P, Genrich J (1997) Southern California permanent GPS Geodetic Array - spatial filtering of daily positions for estimating coseismic and postseismic displacements induced by the 1992 Landers earthquake. J Geophys Res 102(B8):18057-18070

Whitehouse P, Latychev K, Milne GA, Mitrovica JX, Kendall R (2006) Impact of 3-D Earth structure on Fennoscandian glacial isostatic adjustment: implications for space-geodetic estimates of present-day crustal deformations. Geophys Res Lett 33:L13502. doi:10.1029/2006GL026568

Williams SDP (2003) Offsets in global positioning system time series. J Geophys Res 108(B6):2310. doi: 10.1029/2002JB002156

Williams SDP, Bock Y, Fang P, Jamason P, Nikolaidis RM, Prawirodirdjo L, Miller M, Johnson DJ (2004) Error analysis of continuous GPS position time series. J Geophys Res Solid Earth 109:B03412. doi: 10.1029/2003JB002741

Willis MJ (2008) Technologies to operate year-round remote global navigation satellite system (GNSS) stations in extreme environments. In: Capra A, Dietrich R (eds) Geodetic and geophysical observations in Antarctica. Springer, Berlin, pp 11-35

Willis P, Deleflie F, Barlier F (2005) Effects of thermosphere total density perturbations on LEO orbits during severe geomagnetic conditions (Oct-Nov 2003) using DORIS and SLR data. Adv Space Res 36(3):522-533

Willis P, Ries JC, Zelensky NP, Soudarin L, Fagard H, Pavlis EC, Lemoine FG (2009) DPOD2005: an extension of ITRF2005 for precise orbit determination. Adv Space Res 44(5):535-544. doi:10.1016/ j.asr.2009.04.018

Wöppelmann G, Letetrel C, Santamaria A, Bouin MN, Collilieux X, Altamimi Z, Williams SDP, Miguez BM (2009) Rates of sea-level change over the past century in a geocentric reference frame. Geophys Res Lett 36:L12607. doi:10.1029/2009GL038720

Wouters B, Chambers D, Schrama EJO (2008) GRACE observes small-scale mass loss in Greenland. Geophys Res Lett 35(20):5

Wübbena G, Schmitz M (2008) GPS block II/IIA antenna calibration with the Geo ++ robot. In: Proceeings of IGS workshop 2008, Miami Beach, Florida, USA, June 2-6, 2008

Wyatt F (1982) Displacement of surface monuments—horizontal motion. J Geophys Res 87(NB2):979-989

Wyatt FK (1989) Displacement of surface monuments-vertical motion. J Geophys Res Solid Earth Planet 94(B2):1655-1664

Wyatt FK, Bolton H, Bralla S, Agnew D (1989) New designs of geodetic monuments for use with GPS. Eos Trans AGU 70:1054

Yan H, Chen W, Zhu Y, Zhang W, Zhong M (2009) Contributions of thermal expansion of monuments and nearby bedrock to observed GPS height changes. Geophys Res Lett 36:L13301. doi:10.1029/ 2009GL038152

Yuan LG, Ding XL, Zhong P, Chen W, Huang DF (2009) Estimates of ocean tide loading displacements and its impact on position time series in Hong Kong using a dense continuous GPS network. J Geod 83(11):999-1015. doi:10.1007/s00190-009-0319-0

Zanutta A, Vittuari L, Gandolfi S (2008) Geodetic GPS-based analysis of recent crustal motions in Victoria Land (Antarctica). Global Planet Change 62(1-2):115-131 
Zerbini S, Matonti F, Raicich F, Richter B, van Dam T (2004) Observing and assessing nontidal ocean loading using ocean, continuous GPS and gravity data in the Adriatic area. Geophys Res Lett 31(23): art. no.-L23609

Zhang J, Bock Y, Johnson H, Fang P, Williams S, Genrich J, Wdowinski S, Behr J (1997) Southern California permanent GPS geodetic array-error analysis of daily position estimates and site velocities. J Geophys Res 102(B8):18035-18055

Ziebart M, Adhya S, Sibthorpe A, Edwards S, Cross P (2005) Combined radiation pressure and thermal modelling of complex satellites: algorithms and on-orbit tests. Adv Space Res 36(3):424-430

Zielinski JB (1988) Covariance in 3D networks resulting from orbital errors. In: GPS-techniques applied to geodesy and surveying. Springer, Berlin, pp 504-514 